\title{
Diffusive-Dispersive and Reactive Fronts in Porous Media Iron(II) Oxidation at the Unsaturated-Saturated Interface
}

Haberer, Christina M. ; Muniruzzaman, Muhammad; Grathwohl, Peter ; Rolle, Massimo

Published in:

Vadose Zone Journal

Link to article, DOI:

10.2136/vzj2014.07.0091

Publication date:

2015

Document Version

Peer reviewed version

Link back to DTU Orbit

Citation (APA):

Haberer, C. M., Muniruzzaman, M., Grathwohl, P., \& Rolle, M. (2015). Diffusive-Dispersive and Reactive Fronts in Porous Media: Iron(II) Oxidation at the Unsaturated-Saturated Interface. Vadose Zone Journal, 14(5). https://doi.org/10.2136/vzj2014.07.0091

\section{General rights}

Copyright and moral rights for the publications made accessible in the public portal are retained by the authors and/or other copyright owners and it is a condition of accessing publications that users recognise and abide by the legal requirements associated with these rights.

- Users may download and print one copy of any publication from the public portal for the purpose of private study or research.

- You may not further distribute the material or use it for any profit-making activity or commercial gain

- You may freely distribute the URL identifying the publication in the public portal 
This is a Post Print of the article published on line $23^{\text {rd }}$ February 2015 and printed July 2015 in Vadose Zone Journal, 14, No. 5. The publishers' version is available at the permanent link: doi: $\underline{10.2136 / \mathrm{vzj} 2014.07 .0091}$

\title{
Diffusive/Dispersive and Reactive Fronts in Porous Media: Fe(II)-Oxidation at the Unsaturated/Saturated Interface
}

Christina M. Haberer ${ }^{1} *$, Muhammad Muniruzzaman ${ }^{1}$, Peter Grathwohl ${ }^{1}$, Massimo Rolle ${ }^{1,2,3}$

\author{
${ }^{1}$ Center for Applied Geoscience, University of Tübingen, Hölderlinstrasse 12, \\ D-72074 Tübingen, Germany \\ ${ }^{2}$ Department of Civil and Environmental Engineering, Stanford University, 473 Via Ortega, \\ 94305, Stanford, CA, USA \\ ${ }^{3}$ Department of Environmental Engineering, Technical University of Denmark, Miljøvej Building \\ 115, DK-2800 Lyngby, Denmark \\ *corresponding author: $\quad$ christina.haberer@uni-tuebingen.de
}

\section{Impact Statement}

Using a combined experimental and modeling approach we investigate the coupling between diffusive/dispersive processes and kinetic iron(II) oxidation in batch, 1-D column, and 2-D flow-through systems. 


\section{Abstract}

2 Diffusive/dispersive mass transfer is important for many groundwater quality problems as it drives the

3 interaction between different reactants, thus influencing a wide variety of biogeochemical processes. In

4 this study we performed laboratory experiments to quantify oxygen transport in porous media, across the

5 unsaturated/saturated interface, under both conservative and reactive transport conditions. As reactive

6 system we considered the abiotic oxidation of ferrous iron in the presence of oxygen. We studied the

7 reaction kinetics in batch experiments and its coupling with diffusive and dispersive transport processes

8 by means of 1-D columns and 2-D flow-through experiments, respectively. A non-invasive optode

9 technique was used to track oxygen transport into the initially anoxic porous media at highly resolved

10 spatial and temporal scales. The results show significant differences in the propagation of the conservative

11 and reactive oxygen fronts. Under reactive conditions oxygen, continuously provided from the

12 atmosphere, was considerably retarded due to the interaction with dissolved iron(II), initially present in

13 the anoxic groundwater. The reaction between dissolved oxygen and ferrous iron led to the formation of

14 an iron(III) precipitation zone in the experiments. Reactive transport modeling based on a kinetic

15 PHREEQC module tested in controlled batch experiments allowed a quantitative interpretation of the

16 experimental results in both 1-D and 2-D setups.

17 Keywords: diffusion; transverse dispersion; unsaturated/saturated interface; iron(II) oxidation; porous media.

19 In natural systems, the geochemical and biological activity at the interface between different

20 compartments, such as the unsaturated and the saturated zone in the subsurface, is determined by the

21 fluxes and exchange rates across the interface. Interface regions are highly active in terms of

22 physicochemical and microbiological processes (e.g., Sobolev and Roden, 2001; Bauer et al., 2009; Jost et

23 al., 2014). A number of experimental and modeling studies have identified diffusive and dispersive

24 processes as key mechanisms for mass transfer of volatile compounds to or from groundwater systems

25 (e.g., Barber and Davis, 1987; Barber et al., 1990; McCarthy and Johnson, 1993; Klenk and Grathwohl,

26 2002; Werner and Höhener, 2002; Prommer et al., 2009; Haberer et al., 2011, 2012; Freitas et al., 2011). 
27 Of particular importance is the mass transfer of oxygen to anoxic groundwater since dissolved oxygen

28 plays a key role for many biogeochemical processes. The supply of oxygen influences the subsurface 29 redox conditions and the rates of many biological and geochemical reactions (e.g., Stumm and Morgan, 30 1996; Chapelle, 2001; Mächler et al., 2013; Rezanezhad et al., 2014). The importance of oxygen transport 31 across the capillary fringe has been shown in detailed experimental and modeling studies focusing on 32 conservative transport (e.g., Williams and Oostrom, 2000; Haberer et al., 2011, 2014a, 2014b), 33 microbially-mediated reactions (e.g., Sobolev and Roden, 2001; Maier et al., 2007; Dobson et al., 2007;

34 Jost et al., 2014), and abiotic reactions (Farnsworth et al., 2012). The objective of this work is the 35 simultaneous investigation of diffusive/dispersive oxygen transport under conservative and reactive 36 conditions. As a reactive system we selected the abiotic oxidation of ferrous iron that is a process of great 37 environmental relevance in shallow groundwater systems (e.g., Sung and Morgan, 1980; Appelo et al., 38 1999; Appelo and Postma, 2005; Martin, 2005; Vencelides et al., 2007). In fact, iron(II) oxidation affects 39 the mobility and fate of many organic and inorganic contaminants. One notable example is the coupling of 40 iron cycling with arsenic release and transport (e.g., Smedley and Kinniburgh, 2002; Stollenwerk, 2003;

41 Wallis et al., 2011; Sharma et al., 2011; Voegelin et al., 2014). Dissolved ferrous iron is a common 42 constituent of anoxic groundwater and, when it comes into contact with dissolved oxygen, it is oxidized to 43 ferric iron. Once ferric iron is formed it readily undergoes hydrolysis and precipitates as solid ferric 44 hydroxides $\left(\mathrm{Fe}(\mathrm{OH})_{3}\right)$. With time, ferric hydroxides are transformed into progressively more stable and 45 crystalline minerals such as maghemite, lepidocrocite, hematite, and goethite (e.g., Sung and Morgan, 46 1980; Cornell and Schwertmann, 2003; Martin, 2005; Voegelin et al., 2010), which are the principal forms 47 of mineralized ferric iron found in soils and aquifer sediments. Changes in redox and $\mathrm{pH}$ conditions 48 influence iron speciation as well as the kinetics of iron(II) oxidation (Stumm and Morgan, 1996; Frini and 49 Maaoui, 1997).

50 In this study, we experimentally investigate the coupling of abiotic iron(II) oxidation and transport 51 processes in porous media. We focus on the interface between the unsaturated and the saturated zone and 52 we perform $(i)$ reactive batch experiments to characterize the kinetics of iron(II) oxidation under different 
$53 \mathrm{pH}$ conditions and in the presence and absence of a catalyzer; (ii) 1-D conservative and reactive column

54 experiments to investigate the propagation of oxygen fronts under diffusive conditions; and (iii) 2-D flow-

55 through experiments to quantify oxygen transfer across the capillary fringe and the propagation of

56 conservative and reactive fronts under advection-dominated flow-through conditions. Numerical transport

57 simulations have been carried out to interpret the experimental results and to assess the implications of the

58 experimental findings at larger temporal and spatial scales.

\section{THEORETICAL BACKGROUND}

\section{Diffusive/Dispersive Transport in Porous Media}

62 A correct description of diffusive/dispersive processes in porous media is of primary importance since

63 these physical processes determine the transport and distribution of chemical species in the subsurface.

64 Such processes are typically coupled and often limit the overall rate of biogeochemical reactions. In the

65 absence of advective movement of groundwater, diffusion is the main process governing solute transport.

66 In porous media, diffusion of a dissolved species is hindered by the reduced cross-sectional area available

67 for the movement of solute molecules as well as by the size and the tortuous nature of the pores (e.g.,

68 Shackelford, 1991; Grathwohl, 1998; Appelo and Postma, 2005). In a 1-D porous medium diffusive

69 transport of a conservative solute is described as:

$70 \quad \varepsilon \frac{\partial C(z, t)}{\partial t}=D_{p} \varepsilon \frac{\partial^{2} C(z, t)}{\partial z^{2}}$

71 where $C\left[\mathrm{M} \mathrm{L}^{-3}\right]$ is the concentration of the diffusing compound depending on distance, $z$ [L], and time, $t$

$72[\mathrm{~T}], \varepsilon[-]$ represents the porosity, and $D_{p}\left[\mathrm{~L} \mathrm{~T}^{-2}\right]$ is the pore diffusion coefficient. The latter is related to the

73 aqueous diffusivity of the dissolved species as well as to the properties of the porous medium by (e.g.,

74 Boudreau, 1996; Sabatini, 2000; Boving and Grathwohl, 2001; Delgado, 2006):

$75 \quad D_{p}=\frac{D_{a q}}{\tau} \approx D_{a q} \varepsilon^{m-1}$ 
76 where $\tau[-]$ is the tortuosity, a coefficient encompassing the effects of all geometrical and chemical

77 interactions on the apparent diffusional constant in the porous medium $\left(D_{p}\right)$ compared to that found in free

78 aqueous solution, $D_{a q}\left[\mathrm{~L}^{2} \mathrm{~T}^{-1}\right]$ (Clennel, 1997). The right hand side of Eqn. 2 is a common empirical model

79 relating the pore diffusion coefficient to the porosity of the packed bed (e.g., Epstein 1989; Boudreau,

80 1996; Grathwohl 1998; Boving and Grathwohl, 2001; Hu and Wang, 2003). $m$ [-] is an empirical exponent

81 for which different values have been reported in the literature. For instance, Peng et al. (2012) reported a

82 value of 1.33 for soils, a range from 1.92-2.93 for limestone and sandstone, and a range from 2.5-5.4 for

83 clays.

84 For the 1-D diffusion experiments at the unsaturated/saturated interface performed in this study, the

85 following boundary conditions apply:

86

$$
C=C_{b g} \text { at } t=0 \text { for } 0<z \leq \infty
$$

$$
\begin{aligned}
& C=C_{0} \text { at } z=0 \text { for } t \geq 0 \\
& C=C_{b g} \text { at } z \rightarrow \infty \text { for } t \geq 0
\end{aligned}
$$

87 Under these conditions, the analytical solution of the 1-D diffusion equation (Eqn. 1) is:

$88 \quad C_{n o r m}=\frac{C-C_{b g}}{C_{0}-C_{b g}}=\operatorname{erfc}\left(\frac{z}{2 \sqrt{D_{p} t}}\right)$

89 where the concentration of the diffusing compound is normalized by the background concentration

90 prevailing in the porous medium, $C_{b g}\left[\mathrm{M} \mathrm{L}^{-3}\right]$, and the concentration at the unsaturated/saturated interface,

$91 C_{0}\left[\mathrm{M} \mathrm{L}^{-3}\right]$. This analytical solution is used to analyze the results of the conservative transport experiments

92 in the 1-D setup and to estimate the value of the pore diffusion coefficient.

93 Under flow-through conditions solute transport of a conservative species is determined by advective and

94 dispersive processes. Considering a 2-D domain, the governing transport equation reads as:

$95 \quad \frac{\partial C}{\partial t}=D_{L} \frac{\partial^{2} C}{\partial x^{2}}+D_{T} \frac{\partial^{2} C}{\partial z^{2}}-v \frac{\partial C}{\partial x}$

96 where $v\left[\mathrm{~L} \mathrm{~T}^{-1}\right]$ is the seepage velocity, and $D_{L}\left[\mathrm{~L}^{2} \mathrm{~T}^{-1}\right]$ and $D_{T}\left[\mathrm{~L}^{2} \mathrm{~T}^{-1}\right]$ are the longitudinal and transverse

97 components of the hydrodynamic dispersion tensor, respectively. 
98 Mass transfer and mixing in the transverse direction are typically more important in subsurface transport 99 problems (e.g., Kitanidis, 1994); particularly for a continuous release of dissolved species, as in the flow100 through experiments performed in this study, for which the concentration gradients in the longitudinal 101 direction become negligible compared to the ones in the transverse direction (e.g., Chiogna et al., 2011 102 and 2012). Thus, an accurate description of the transverse hydrodynamic dispersion coefficient is 103 fundamental to properly describe dilution and reactive mixing processes. Recent pore-scale and laboratory 104 studies have shown the important interplay between the fundamental physical processes of advection and 105 diffusion not only at slow but also at high seepage velocities, resulting in compound-specific incomplete 106 dilution in the pore channels (Rolle et al., 2012; Rolle and Kitanidis, 2014) and influencing the transport 107 of uncharged polyatomic species as well as charged ions in porous media (Rolle et al., 2013a, 108 Muniruzzaman et al., 2014). Such effects at the subcontinuum scale propagate and are relevant also at 109 larger macroscopic scales (Rolle et al., 2013b). Hence, such effects need to be captured in dispersion 110 parameterizations at the continuum scale. An example is the compound-specific model for transverse 111 dispersion proposed by Chiogna et al. (2010). This parameterization of $D_{T}$, inspired by an earlier statistical 112 model of Bear and Bachmat (1967), takes into account the influence of aqueous diffusion not only on the 113 pore diffusion but also on the mechanical dispersion term:

$114 \quad D_{T}=D_{p}+D_{a q}\left(\frac{P e^{2}}{P e+2+4 \delta^{2}}\right)^{\beta}$

115 where $P e=v d / D_{a q}$ is the dimensionless grain Péclet number with $d[\mathrm{~L}]$ representing the grain diameter, $\delta$ $116[-]$ is the ratio between the length of a pore channel and its hydraulic radius, and $\beta$ [-] is an exponent 117 accounting for incomplete dilution of the solute in the pore channels. Average values of $\delta=6.2$ and $\beta=$ 1180.5 were determined experimentally considering a wide range of flow-through conditions in different 119 porous media and were found in good agreement with the outcomes of pore-scale simulations (Rolle et al., 120 2012, Hochstetler et al., 2013).

121 In reactive systems coupled transport and biogeochemical transformation occurs. In the description of 122 such systems, the reactive terms are included in the governing diffusion and advection-dispersion 
124 oxygen, for which the reactive term is described in the following section.

127 The abiotic oxidation of ferrous iron in the presence of oxygen is described by the following chemical 128 reaction:

$$
\mathrm{Fe}^{2+}+0.25 \mathrm{O}_{2}+2.5 \mathrm{H}_{2} \mathrm{O} \rightarrow \mathrm{Fe}(\mathrm{OH})_{3}(\mathrm{~s})+2 \mathrm{H}^{+}
$$

130 An intermediate step in this overall chemical reaction is the formation of ferric iron, which readily 131 undergoes hydrolysis and precipitates as solid ferric hydroxide (Cornell and Schwertmann, 2003).

132 Depending on the solution's $\mathrm{pH}$ and temperature, as well as on the ions participating in the reaction, the 133 presence of organic constituents and oxidizing agents, various oxidation products are formed in different 134 ratios (e.g., Stumm and Morgan, 1996; Voegelin et al., 2010). As an example, the slow oxidation of 135 ferrous iron due to aeration can result in the formation of magnetite, lepidocrocite, hematite, and goethite 136 (e.g., Frini and Maaoui, 1997). The oxidation of iron(II) (Eqn. 7) also results in the formation of $\mathrm{H}^{+}$-ions 137 and thus, depending on the buffering capability of the system, in a possible decrease of $\mathrm{pH}$.

138 Due to the importance of iron(II) oxidation in many aquatic systems, the kinetics of this reactive process 139 has been extensively studied. In aqueous solutions at $\mathrm{pH} \geq 5$ the oxygenation kinetics of ferrous iron 140 follows the general rate law (e.g., Stumm and Lee, 1961; Sung and Morgan, 1980; Davison and Seed, 141 1983; Millero et al.1987; Stumm and Morgan, 1996):

$142-\frac{d\left[\mathrm{Fe}^{2+}\right]}{d t}=k^{*}\left[\mathrm{Fe}^{2+}\right]\left[\mathrm{OH}^{-}\right]^{2} p_{\mathrm{O}_{2}}$

143 where $k^{*}$ is the reaction rate constant for which Stumm and Morgan (1996) report a value of $8( \pm 2.5) \times 10^{13}$

$144 \mathrm{~mol}^{-2} \mathrm{~L}^{2} \mathrm{~atm}^{-1} \mathrm{~min}^{-1}$ at $20{ }^{\circ} \mathrm{C}$. Expressing the dependence on oxygen as function of the dissolved aqueous 145 concentration, the rate law reads as:

$146-\frac{d\left[F e^{2+}\right]}{d t}=k\left[F^{2+}\right]\left[O H^{-}\right]^{2}\left[O_{2}(a q)\right]$ 
147 in which the reaction rate constant, $k$, now has units of $\operatorname{mol}^{-3} \mathrm{~L}^{3} \mathrm{~min}^{-1}$.

148 According to Eqs. 8 and 9, the oxidation rate of ferrous iron is of first-order with respect to the 149 concentration of both ferrous iron and oxygen, whereas it is of second-order with respect to $\mathrm{pH}$. Therefore, 150 the reaction rate is strongly $\mathrm{pH}$-dependent, and below $\mathrm{pH} 6$ the oxidation of ferrous iron is very slow (e.g.,

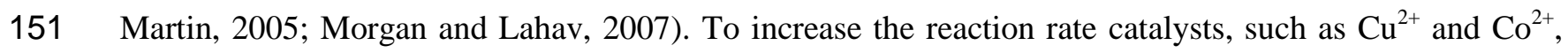
152 may be added in trace quantities (Stumm and Lee, 1961; Stumm and Morgan, 1996).

153 Abiotic iron(II) oxidation may not only occur by direct oxidation of ferrous iron in the solution

154 (homogeneous reaction), but also by specific adsorption of ferrous iron to hydrous oxide surfaces (e.g., 155 Stumm and Morgan, 1996; Park and Dempsey, 2005; Schmidt et al., 2009). Iron (hydr)oxides, formed as 156 reaction products in the homogeneous oxidation of iron(II), may further accelerate the reaction rate by 157 providing a surface for the autocatalytic oxidation. The autocatalytic oxidation process depends on the 158 amount of ferric iron (Wolthoorn et al., 2004) and is noticeable only for $\mathrm{pH}$-values greater than about $\mathrm{pH}$ 1597 (Sung and Morgan, 1980). At $\mathrm{pH}$-values greater than 7 the oxidation of ferrous iron is a mixture of both 160 the homogeneous and the autocatalytic process with the former representing the dominating mechanism at 161 circumneutral pH (Wolthoorn et al., 2004). Hence, only the homogeneous reaction rate is considered in 162 this study to describe the abiotic oxidation of ferrous iron.

\section{MATERIAL AND METHODS}

Experimental Setups

166 In the following, we present the different experimental setups used to investigate diffusive/dispersive and

167 reactive transport of oxygen at the interface between the unsaturated and the saturated zone. A schematic 168 overview is given in Fig. 1. We performed batch experiments, 1-D diffusion experiments, and 2-D flow169 through experiments in a thermostatic room at $22^{\circ} \mathrm{C}$.

170

$171<$ Figure $1>$

172 
174 Batch experiments were performed to characterize the abiotic iron(II)-oxidation reaction (Eqn. 7) and to 175 determine the reaction rate constant needed for simulating reactive transport in the 1-D and 2-D 176 experiments ( $k$ in Eqn. 9). In particular, we investigated the impact of $\mathrm{pH}$ and a catalyzer $\left(\mathrm{Cu}^{2+}\right)$ on the 177 observed reaction rate. Table 1 summarizes the different conditions tested.

Before starting the experiments, four $250 \mathrm{~mL}$-Schott bottles were equipped with an oxygen-sensitive sensor spot (SP-PSt3-NAU from PreSens GmbH, Regensburg, Germany). The sensor spot was attached to the inner wall of each Schott bottle to facilitate oxygen measurement during the experiment by applying a 184 non-invasive optode technique (Fibox3 from PreSens GmbH, Regensburg, Germany; e.g., Haberer et al., 185 2011). Subsequently, the Schott bottles were filled with $250 \mathrm{~mL}$ air-equilibrated MilliQ water. To keep pH 186 stable and to avoid mineral precipitation, an organic $\mathrm{pH}$ buffer (here: PIPES, CAS: 5625-37-6, with $\mathrm{pK}_{\mathrm{a}}=$ 1876.80 at $20^{\circ} \mathrm{C}$; Good et al., 1966) was added in experiments B, C, and D with a concentration of c(PIPES) $188=1 \times 10^{-3} \mathrm{~mol} \mathrm{~L}^{-1}$. Complete dissolution of the $\mathrm{pH}$ buffer was achieved by heating up the solutions and 189 allowing them to cool down to room temperature. To investigate the effect of a catalyzer we also added $190 \mathrm{CuSO}_{4}$ to one of the Schott bottles (Batch D; $\mathrm{c}\left(\mathrm{Cu}^{2+}\right)=3 \times 10^{-7} \mathrm{~mol} \mathrm{~L}^{-1}$ according to Stumm and Lee, 191 1961). If needed $\mathrm{pH}$ was adjusted to the desired initial $\mathrm{pH}$-value with $1 \mathrm{~mol} \mathrm{~L}^{-1} \mathrm{NaOH}$. All Schott bottles 192 were stirred continuously to achieve uniform distribution of the reactants and to enhance oxygen resupply 193 from the atmosphere. After addition of $\mathrm{Fe}^{2+}$ as $\mathrm{FeCl}_{2} \cdot 4 \mathrm{H}_{2} \mathrm{O}$ (CAS: $13478-10-9$, final concentration: $\mathrm{c}\left(\mathrm{Fe}^{2+}\right)$ $\left.194=1.79 \times 10^{-4} \mathrm{~mol} \mathrm{~L}^{-1}\right)$, we followed $\mathrm{c}\left(\mathrm{O}_{2}\right), \mathrm{pH}, \mathrm{c}\left(\mathrm{Fe}^{2+}\right)$, and $\mathrm{c}\left(\mathrm{Fe}_{\mathrm{tot}}\right)$ over time. During the experiment, the 195 oxygen concentration was detected with an optical fiber from the outside, $\mathrm{pH}$ was measured with a pH196 electrode (pH 540 GLP, WTW Wissenschaftlich-Technische Werkstätten GmbH, Weilheim, Germany), 197 and water samples were taken to determine the concentrations of $\mathrm{Fe}^{2+}$ and $\mathrm{Fe}_{\text {tot }}$ by performing a ferrozine 198 assay (Stookey, 1970; Viollier et al., 2000). To prevent oxidation of ferrous iron before the analysis, we 
199 diluted the samples with $1 \mathrm{~mol} \mathrm{~L}^{-1} \mathrm{HCl}$ in a 1:1 ratio. An additional dilution step, using multiwell plates, 200 was necessary to measure $\mathrm{c}\left(\mathrm{Fe}^{2+}\right)$ and $\mathrm{c}\left(\mathrm{Fe}_{\mathrm{tot}}\right)$. That is, $20 \mu \mathrm{L}$ of the diluted sample were again mixed with 201 either $80 \mu \mathrm{L} \mathrm{HCl}\left(\mathrm{c}(\mathrm{HCl})=1 \mathrm{~mol} \mathrm{~L}^{-1}\right)$ to measure ferrous iron, or $80 \mu \mathrm{L}$ hydroxylamine hydrochloride 202 solution (i.e., $10 \%(\mathrm{~m} / \mathrm{v})$ hydroxylamine hydrochloride in $1 \mathrm{~mol} \mathrm{~L}^{-1} \mathrm{HCl}$ ) to measure total iron. $100 \mu \mathrm{L}$ 203 ferrozine solution (50\% (m/v) ammonium acetate with $0.1 \%(\mathrm{~m} / \mathrm{v})$ ferrozine in MilliQ water) were added 204 to each sample to measure the concentration of ferrous iron at a wavelength of $562 \mathrm{~nm}$ using a microplate 205 reader (FLASHScan ${ }^{\circledR} 550$ from Analytik Jena AG, Jena, Germany).

207 1-D diffusion experiments

208 Glass columns (length: $11.6 \mathrm{~cm}$, inner diameter: $1.75 \mathrm{~cm}$ ), filled with a fully water-saturated porous 209 medium, were used to study diffusive conservative and reactive mass transfer of oxygen from the 210 atmosphere to anoxic water (Fig. 1). In particular, we characterized pore diffusion in different porous 211 media (i.e., in glass beads and in River Rhine sand with grain diameters of 0.4-0.6 mm) under 212 conservative conditions and we investigated the impact of abiotic iron(II) oxidation on oxygen transport in 213 1-D reactive transport experiments, using the same conditions and reaction kinetics investigated in the 214 batch systems (experiment B). In the conservative setup an initial solution identical to the one prepared for 215 batch system B (Table 1), but without addition of ferrous iron, was used as pore water solution; in the 216 reactive case we additionally added ferrous iron with a concentration of $1.79 \times 10^{-4} \mathrm{~mol} \mathrm{~L}^{-1}$. Such solutions 217 were flushed with nitrogen and stored in Tedlar® gas sampling bags.

218 Before starting the experiment, we glued an oxygen-sensitive sensor strip (SP-PSt3-NAU from PreSens $219 \mathrm{GmbH}$, Regensburg, Germany) with dimensions of $4.7 \mathrm{~cm} \times 0.5 \mathrm{~cm}$ onto the inner wall of the glass 220 column (Fig. 1) to obtain temporal and spatial profiles of oxygen concentration in one experimental run.

221 The glass column was placed into a polystyrene box (Fig. 2) to minimize temperature effects and to keep 222 humidity high, thus resulting in minimal evaporation rates and, hence, in the approximately constant 223 location of the unsaturated/saturated interface. During the experiment temperature was recorded and used 224 for temperature compensation of the measured oxygen concentrations. Moreover, the evaporation rate was 
determined with a separate column (with same dimensions as the measurement column and filled with the

226 same fully water-saturated porous medium) based on weight measurements at the beginning and at the end

227 of the experiment.

228

$<$ Figure $2>$

230

231 To prepare the setup the glass columns were closed on one end using screw caps with silicon/PTFE septa.

232 Before filling the measurement vial, we pierced hollow needles through the septum of the bottom screw

233 cap. The needles were connected to pump tubing, through which we injected the prepared anoxic solutions

234 into the column using a peristaltic pump (IPC 12, IDEX Health and Science GmbH, Wertheim, Germany).

235 Subsequently, the porous medium was filled into the column, always keeping the water table above the

236 upper limit of the porous medium packing. When the column was packed completely, a second cap was

237 screwed onto the measurement vial and a hollow needle was punched through the septum to facilitate

238 upward flow (Fig. 2). The anoxic solution was flushed through the system until a constant low background

239 concentration of oxygen was measured.

240 We started the experiment (time $=0$ ) by switching off the inlet pump (no-flow condition), unscrewing the

241 upper cap, and removing the supernatant liquid in the measurement vial, such that the water meniscus,

242 representing the unsaturated/saturated interface, was at the upper limit of the porous medium packing.

243 Oxygen immediately started to diffuse into the anoxic porous medium (Fig. 2) and we measured the

244 breakthrough of oxygen concentrations at a specific point $(13 \mathrm{~mm})$ below the porous medium/atmosphere

245 interface as a function of time (10 s intervals). Additionally, every three to six hours the oxygen

246 distribution in the column was determined by measuring spatial profiles of oxygen concentration at high

247 resolution $(2.5 \mathrm{~mm})$ along the oxygen-sensitive sensor strip. 
251 the column:

252

$$
\varepsilon=\frac{V_{w}}{V_{\text {tot }}}=\frac{\frac{m_{w}}{\rho_{w}}}{\frac{m_{w}}{\rho_{w}}+\frac{m_{s}}{\rho_{s}}}
$$

253 where $V_{w}\left[\mathrm{~L}^{3}\right]$ and $V_{t o t}\left[\mathrm{~L}^{3}\right]$ are the volumes of the water and the porous medium packing, $m_{w}[\mathrm{M}]$ and $m_{s}$

$254[\mathrm{M}]$ are the masses of the water and the solid phase, and $\rho_{w}\left[\mathrm{M} \mathrm{L}^{-3}\right]$ and $\rho_{s}\left[\mathrm{M} \mathrm{L}^{-3}\right]$ are the density of the 255 water and the solid phase, respectively.

\section{2-D flow-through experiments}

258 Flow-through experiments were performed to investigate the propagation of dispersive oxygen fronts in a 259 quasi 2-D setup. The flow-through chamber was constructed with two 5-mm thick glass panes, separated 260 by a Viton ${ }^{\circledR}$ septum, and had inner dimensions of $16.2 \mathrm{~cm}$ (length, $\left.L\right) \times 12.7 \mathrm{~cm}$ (height, $H$ ) $\times 0.5 \mathrm{~cm}$ 261 (width, $W$ ). An oxygen-sensitive sensor strip was glued onto the inner wall of the chamber (at $x=13 \mathrm{~cm}$ 262 from the inlet, see Fig. 1) to detect oxygen concentrations at high spatial resolution (2.5 mm spacing). We 263 filled the flow-through chamber with glass beads with grain diameters of $d=0.4-0.6 \mathrm{~mm}$. At the inlet and

264 at the outlet of the chamber, hollow needles, connected to pump tubing (Fluran-HCA, ID $0.64 \mathrm{~mm}$ from 265 IDEX Health \& Science GmbH), were pierced through the Viton® septum separating the two glass panes. 266 These needles were equally spaced by $0.75 \mathrm{~cm}$, and served as inlet (12 ports) and outlet ports (13 ports) to 267 induce a horizontal flow-field in the chamber during the experiment by means of two high-precision 268 peristaltic pumps (IPC-N 24, IDEX Health \& Science GmbH). An overview of the porous medium 269 properties and of the flow and transport parameters in the 2-D setup is given in Table 2. 
273 The conservative and reactive transport experiments were performed under the same conditions as the 1-D 274 column systems, i.e., using anoxic buffered solutions without and with addition of ferrous iron, 275 respectively (the latter solution corresponding to Batch B, Table 1). To minimize the contamination of the 276 prepared anoxic solutions by atmospheric oxygen, after flushing the solutions with nitrogen, we added a 277 small amount of ascorbic acid (CAS: 50-81-7) resulting in a concentration of $6.25 \times 10^{-5} \mathrm{~mol} \mathrm{~L}^{-1}$. 278 Subsequently, the $\mathrm{pH}$ of the solutions was adjusted to the desired value of 7 . Similarly, to minimize 279 oxygen contamination on the long term of the flow-through experiments (days to weeks) we placed an 280 AnaeroGen sachet (Fisher Scientific, Schwerte, Germany) in the gas phase of the glass bottles that were 281 used to store the inlet solutions. The ascorbic acid in the sachet absorbed oxygen, which reduced the 282 oxygen content in the gaseous phase to below $1 \%$. To extract water from the glass bottles and pump it in 283 the flow-through setup, a thoroughly nitrogen-flushed Tedlar® gas sampling bag, serving as gas reservoir, 284 was connected to the reservoir of the inlet anoxic solution (Fig. 1).

285 After flushing the system with at least two pore volumes, high-resolution vertical oxygen profiles were 286 measured along the oxygen-sensitive sensor strip located close to the outlet of the flow-through chamber.

\section{Modeling Approach}

289 Numerical modeling was performed to quantitatively evaluate the experimental results in the batch, 1-D and 2-D systems. A reactive module for kinetic oxidation of ferrous iron was developed using the geochemical code PHREEQC-3 (Parkhurst and Appelo, 2013). The module was first developed for batch conditions and validated with the experimental dataset B (Table 1). The stoichiometry of ferrous iron oxidation was described as in the balanced redox reaction (Eqn. 7); the kinetics of iron(II) oxidation was

294 implemented according to Eqn. 9. To simulate the reaction kinetics we decoupled the valence states of 295 ferrous and ferric iron, following an approach similar to the one described in example 9 of Parkhurst and 296 Appelo (2013), and we allowed the precipitation of ferrihydrite. Mimicking the experimental conditions, 297 we used the same initial concentration of the major reactants (ferrous iron and dissolved oxygen) and a pH 298 buffer with identical concentration and pKa of PIPES (Table 1). The only parameter that was adjusted was 
the specific rate constant of iron(II) oxidation ( $k$ in Eqn. 9). To this end, we took advantage of the new

300 capabilities of the recently released IPHREEQC, and specifically of IPHREEQC-COM which allows 301 performing all geochemical PHREEQC calculations directly from MATLAB as well as from any other 302 software that can interface with a COM (component object model) server (Charlton and Parkhurst, 2011; 303 Wissmeier and Barry, 2011). Thus, an automatic fitting routine based on the trust-region-reflective 304 algorithm implemented in the MATLAB function lsqnonlin was used to determine the value of the 305 reaction rate constant through the minimization of the non-linear least squares problem between the 306 computed and measured concentrations.

307 The PHREEQC module for kinetic iron(II) oxidation was directly applied in the 1-D and 2-D systems.

308 The simulation of the diffusive/reactive transport in the 1-D column setup was performed in PHREEQC, 309 where the $10 \mathrm{~cm}$ saturated porous medium domain was discretized into 100 cells $(\Delta z=1 \mathrm{~mm})$. The 310 simulations were performed for simulation times corresponding to the experimental duration and the 311 spatial and temporal profiles obtained from the model runs were compared to the experimental 312 measurements.

313 Flow and transport simulations were performed for the 2-D flow-through system. Since this and previous 314 experimental studies conducted using similar porous media (e.g., Haberer et al., 2011) have shown that a 315 sharp interface between the unsaturated and the underlying fully water-saturated zone can be identified, 316 and that steep oxygen gradients form only in the saturated zone, the system can be accurately described by 317 exclusively focusing on the fully water-saturated medium. Thus, we solved the flow problem using the 318 code MODFLOW (Harbaugh, 2005) and the transport problem with PHT3D (Prommer et al., 2003), 319 which couples the solute transport code MT3DMS (Zheng and Wang, 1999) with PHREEQC. The 320 geometry and the boundary conditions in the 2-D model closely represent the experimental setup and a 321 fine discretization (grid cells with $\Delta x$ and $\Delta z$ up to 0.5 and $0.25 \mathrm{~mm}$, respectively) was used to allow 322 capturing the steep concentration gradients observed in the experimental setup. 


\section{RESULTS AND DISCUSSION}

Batch Experiments

327 Batch experiments were performed to study the kinetics of iron(II) oxidation under different conditions.

328 Figure 3 shows the time-dependent reduction in ferrous iron concentration for the batch experiments 329 summarized in Table 1. In Batch A, no buffer was added to the solution and we measured a rapid decrease 330 in $\mathrm{pH}$ from 7 to 5.5. This caused a significant decrease in the reaction rate, which strongly depends on $\mathrm{pH}$ 331 (Eqs. 8 and 9), and thus only a slight decrease of the ferrous iron concentration was observed. In Batch B 332 the $\mathrm{pH}$ was buffered and the results show a fast oxidation of iron(II) in the solution. Increasing the initial $333 \mathrm{pH}($ Batch $\mathrm{C})$ and adding $\mathrm{CuSO}_{4}$ as catalyzer (Batch D) caused a further increase in the reaction rate and 334 in the oxidation of dissolved ferrous iron.

$<$ Figure $3>$

338 The conditions of Batch B were selected to investigate the impact of kinetic effects on reactive transport in 339 the 1-D and 2-D experiments. Under these conditions, we measured the temporal evolution of dissolved 340 ferrous iron concentration, oxygen, and $\mathrm{pH}$ over a time period of $80 \mathrm{~min}$. The reactive PHREEQC module 341 for kinetic iron(II) oxidation described above was used to simulate the experimental results and to directly 342 obtain a best-fit value for the reaction rate constant (k). As shown in Fig. 4 a reasonably good agreement 343 was found between the experimental data and the results of the simulations for the different parameters 344 measured in the batch experiment. Furthermore, the automated fitting procedure implemented using the

345 capability of IPHREEQC-COM yielded a value of the reaction rate constant of $k=9.84( \pm 0.23) \times 10^{15} \mathrm{~L}^{3}$

$346 \mathrm{~mol}^{-3} \mathrm{~s}^{-1}$ (at $22{ }^{\circ} \mathrm{C}$ ). This value is comparable with previously reported values of reaction rate constants for 347 abiotic ferrous iron oxidation (e.g., Stumm and Lee, 1961; Davison and Seed, 1983; Stumm and Morgan, 348 1996). 
Oxygen diffusive fronts were tracked in the 1-D column setup, and conservative transport experiments were performed in different porous media (i.e., in glass beads and River Rhine sand packings). Figure 5 shows the oxygen concentrations for a conservative diffusion experiment conducted in the 1-D column setup using glass beads with grain diameters $d=0.4-0.6 \mathrm{~mm}$ as porous medium. The symbols represent the measurements, whereas the continuous lines are the modeling results obtained by fitting the analytical solution of the conservative 1-D transport problem (Eqn. 4) to the experimental data. The spatial profiles measured at different time intervals along the oxygen-sensitive sensor strip show a progressive penetration of the oxygen front into the anoxic porous medium (Fig. 5a). The breakthrough of oxygen at the measurement location, $13 \mathrm{~mm}$ below the unsaturated/saturated interface, is shown in Fig. $5 \mathrm{~b}$.

The simultaneous fitting of the analytical solution to the spatial and temporal profiles allowed us to 365 determine the value of the pore diffusion coefficient of oxygen in the packed column. We obtained a value 366 of $D_{p}=1.18 \times 10^{-9} \mathrm{~m}^{2} \mathrm{~s}^{-1}$. Knowing the free aqueous diffusion coefficient for dissolved oxygen (Table 2)

367 the tortuosity of the porous medium can be estimated using Eqn. 2. We obtained a value of tortuosity of

3681.67 for the column packed with glass beads and 1.73 for the one packed with river Rhine sand (Table 3).

369 These values compare well with previously reported results and also with estimates using an empirical 370 correlation with the packed bed porosity (Eqn. 2, right hand side), with an empirical exponent of $m=1.5$

371 (e.g., Bruggeman 1935; Boudreau, 1996; Sabatini, 2000; Boving and Grathwohl, 2001; Delgado, 2006;

372 Coutelieris and Delgado, 2012). 
376 We also performed a reactive experiment in the porous medium packed with glass beads with the aim of

377 investigating the coupling of diffusive oxygen transport with the kinetic oxidation of ferrous iron. The 378 oxygen concentration profiles measured along the oxygen-sensitive sensor strip at specific time intervals 379 are presented in Fig. 6b. Reactive transport simulations were performed with a 1-D PHREEQC model 380 including the pore diffusion coefficient determined in the conservative experiment $\left(D_{p}=1.18 \times 10^{-9} \mathrm{~m}^{2} \mathrm{~s}^{-1}\right)$ 381 and the reaction rate constant obtained from the best fit analysis of the abiotic iron(II) oxidation in the 382 batch system $\left(k=9.84 \times 10^{15} \mathrm{~mol}^{-3} \mathrm{~L}^{3} \mathrm{~s}^{-1}\right.$, Batch B). As can be observed in Fig. $6 \mathrm{~b}$, the pure forward 383 modeling simulations of the reactive system using the experimentally determined transport and reaction

384 parameters are in excellent agreement with the experimental data. In Fig. 6 we also included the spatial 385 profiles of the conservative experiments in the same porous medium as well as the simulation outcomes of 386 a hypothetical case of instantaneous reaction (Liu et al., 2010; Haberer et al., 2011), shown in Fig. 6a and 387 Fig. 6c, respectively.

391 The comparison between the spatial profiles for the three different cases presented in Fig. 6 is illustrative of the propagation of the oxygen fronts in the anoxic porous medium. The location of the oxygen fronts 18 hours after the start of the respective experiment is depicted for the three distinct cases. Due to the absence 394 of a chemical reaction, the penetration depth of oxygen is largest for the conservative case and can be 395 described by:

$396 \quad z_{\text {cons }}=2 \operatorname{erfc}^{-1}\left(C_{\text {norm }}\right) \sqrt{D_{p} t}$

397 where erfc ${ }^{-1}$ is the inverse complementary error function. For $C_{n o r m}=0.05, D_{p}=1.18 \times 10^{-9} \mathrm{~m}^{2} \mathrm{~s}^{-1}$, and $t=$ $39818 \mathrm{~h}$, the penetration depth was $z_{\text {cons }}=25 \mathrm{~mm}$ (Fig. 6a). Tracking the same normalized concentration, 399 significantly smaller penetration depths were obtained in the reactive cases. The smallest penetration 400 depth was found in the case of instantaneous reaction: $z_{\text {reac, } i n s}=17 \mathrm{~mm}$. For the reactive transport 
401 experiments with kinetic iron(II) oxidation, the oxygen profile reached a penetration depth of $z_{\text {reac, }, \text { in }}=18$

$402 \mathrm{~mm}$ that is in-between the conservative and the instantaneous reaction cases, but closer to the latter.

403 The oxygen penetration depth at different times (also for $C_{n o r m}=0.05$ ), corresponding to the measurement

404 of the spatial profiles in the conservative and reactive experiments, as well as the simulation results for the

405 three scenarios discussed above are reported in Fig. 7a. Considering the ratio of the penetration depth

406 increments over time we estimated the velocities of propagation of the oxygen fronts which appear to

407 follow a $1 / \sqrt{t}$-trend. The speed of propagation of the diffusive fronts is larger in the conservative case,

408 whereas for reactive transport the interaction with the dissolved ferrous iron results in the retardation of

409 the oxygen fronts.

$411 \quad<$ Figure $7>$

413 Figure 8 shows the temporal oxygen concentration profiles determined at $13 \mathrm{~mm}$ depth below the 414 unsaturated/saturated interface. The fastest propagation of the oxygen front in the conservative case is 415 reflected also by its earlier breakthrough compared to the observations in the reactive experiments. The 416 breakthrough curves in Fig. 8 also illustrate that the effect of the iron(II)-oxidation kinetics is significant at 417 early times when the experimental and simulated results are clearly distinct from the conservative and 418 instantaneous cases. However, as time progresses the oxygen breakthrough for the kinetic iron(II) 419 oxidation tends to approach the behavior of an instantaneous reaction.

423 Numerical simulations were also performed to further investigate the propagation of conservative and 424 reactive oxygen fronts at spatial and temporal scales beyond the ones considered in the experiments. In 425 these scenarios, besides the three cases illustrated above, we also considered the kinetic oxidation of 426 ferrous iron in an unbuffered system (corresponding to Batch A in Table 1). The results are reported as 
427 spatial profiles in Fig. 9. Over a time period of 0.5 days, comparable with the temporal scale of the 1-D

428 diffusion experiments, the conservative, reactive instantaneous, and buffered reactive kinetic profiles are

429 distinct, whereas the unbuffered reactive kinetic profile overlaps with the conservative case. As time

430 increases $(5,50$, and 500 days) the differences in the velocity of propagation of the oxygen fronts lead to

431 increasingly different penetration depths. Moreover, the profiles for the buffered kinetic system tend to

432 merge with the ones of the instantaneous reactive scenario since under these conditions the relatively fast

433 reaction kinetics is limited by the diffusive transport. Conversely, kinetic effects start to be remarkable for

434 the unbuffered kinetic reaction system at later time as shown by the spatial profiles in Fig. 9b (especially

435 for $t=500$ days). In fact, at later times the slow reaction kinetics, determined by the absence of $\mathrm{pH}$

436 buffering capacity, starts to have a noticeable effect and results in a slower propagation of the oxygen

437 front compared to the conservative case.

438

$439<$ Figure $9>$

\section{Oxygen Dispersive Fronts under Flow-Through Conditions}

442 The impact of the kinetic iron(II)-oxidation reaction on oxygen transfer across the unsaturated/saturated

443 interface was also investigated in a quasi 2-D flow-through system. In such setup we performed

444 sequentially conservative and reactive experiments. First, the flow-through chamber, filled with glass

445 beads with grain diameters in the range of $d=0.4-0.6 \mathrm{~mm}$, was flushed with an anoxic solution,

446 containing the $\mathrm{pH}$-buffer but no ferrous iron, at an average flow velocity of $1.9 \mathrm{~m} \mathrm{~d}^{-1}$. Due to the oxygen

447 gradient between the atmosphere and the anoxic water phase, oxygen was transferred across the

448 unsaturated/saturated interface into the anoxic water. After reaching steady state, we measured the vertical

449 oxygen concentration profile for this conservative experiment at the oxygen-sensitive polymer strip

450 located at $x=13 \mathrm{~cm}$ from the inlet. Successively, we performed the reactive experiment by injecting at the

451 inlet an anoxic solution containing ferrous iron and the $\mathrm{pH}$ buffer. As can be observed in the photograph

452 of Fig. 10a, the contact between dissolved oxygen and ferrous iron caused the precipitation of iron 
453 hydroxides close to the unsaturated/saturated interface. The shape of the iron precipitation zone is also 454 significantly influenced by the flow field in the flow-through system, as substantiated by the flow model 455 and by the computed flow lines (Fig. 10b). Reactive transport was simulated by incorporating the kinetic 456 geochemical PHREEQC module, previously applied in the batch and 1-D system, into the 457 multidimensional transport simulator PHT3D (Prommer et al., 2003). The comparison of the experimental 458 data and the outcome of forward simulations with the same reaction kinetics described above and with the 459 key transport parameter, the local transverse hydrodynamic dispersion coefficient calculated according to 460 Eqn. 6, is shown in Fig. 10c. Despite the limited spatial scale of the setup, a significant difference can 461 already be appreciated between the spatial oxygen profiles in the conservative and reactive experiments.

462 Similarly to the observations in the 1-D diffusion system, also in the flow-through setup the dispersive 463 oxygen front penetrates further in the anoxic porous medium in the case of conservative transport.

467 Figure 11 shows the penetration depth and the velocity of propagation of the dispersive oxygen fronts for 468 two distinct seepage velocities: $v=1.9 \mathrm{~m} \mathrm{~d}^{-1}$ (as in the flow-through experiments) and for a scenario at 469 lower flow velocity, $v=0.19 \mathrm{~m} \mathrm{~d}^{-1}$. The symbols refer to the conservative and kinetic reactive cases and 470 are plotted in the region of the flow-through domain where the flow is approximately horizontal. The 471 penetration depths are larger and more distinct between the conservative and reactive cases for the low 472 flow velocity scenario, due to the tenfold higher residence time of oxygen in the flow-through system. 473 However, as can be observed in Fig. 11b, the velocity of propagation of the dispersive oxygen fronts is 474 considerably larger for the case with higher seepage velocity. 
480 The quantitative understanding of mixing processes in porous media is of critical importance for many 481 environmental applications. A challenging task is to address the coupling between transport and 482 biogeochemical reactions in subsurface environments. This is particularly true for mixing-induced mineral 483 precipitation, which typically occurs along multi-component chemical gradients in narrow mixing zones 484 and at the interface between different compartments. An increasing number of recent studies have 485 addressed the complexity of these reactive systems in porous media (e.g., Tartakovsky et al., 2008; Zhang 486 et al., 2010; Yoon et al. 2012; Molins et al., 2012; Gebrehiwet et al., 2014; Redden et al., 2014). In this 487 work we investigated the abiotic oxidation of ferrous iron resulting in the precipitation of ferric 488 hydroxides at the interface between the unsaturated and the saturated zones. In particular, we focused on 489 the effects of abiotic iron(II) oxidation on the propagation of oxygen fronts in diffusive transport regimes 490 as well as under flow-through conditions. Through the direct comparison of conservative and reactive 491 transport in the same setups, our experiments allow quantifying the significant influence of ferrous iron 492 oxidation on the penetration depth and on the speed of propagation of oxygen fronts in anoxic, water493 saturated porous media. We also show that the chemistry of the anoxic solution, and in particular its $\mathrm{pH}$ 494 buffering capability, plays a significant role in the propagation of oxygen fronts and on the importance of 495 the kinetics of abiotic iron(II) oxidation for reactive transport. In $\mathrm{pH}$-buffered systems we found that the 496 kinetics of iron(II) oxidation becomes less important with increasing time and that at larger time scales the 497 reaction can be described as an instantaneous process. Conversely, the iron(II)-oxidation kinetics can be 498 important also at large time scales in unbuffered systems, where the decrease in pH strongly affects the 499 reaction rates. Thus, under these conditions the slow reaction rate may become the controlling factor in the 500 coupling with typically slow, and thus rate-limiting, diffusive and dispersive processes. Although our 501 study was performed under simplifying conditions compared to physical and chemical heterogeneous 502 groundwater systems, the results on the coupling between transport processes and abiotic ferrous iron 503 oxidation have important implications for relevant subsurface environmental processes such as transport 504 of inorganic contaminants and their interaction with iron minerals (e.g., Smedley and Kinniburgh, 2002), 
505 acidification of groundwater (e.g., Kjøller et al., 2004; Franken et al., 2009), pyrite oxidation (e.g., 506 Prommer and Stuyfzand, 2005), formation of gley soils and oxidized iron mineral inclusions in open 507 framework gravel lenses in braided river sediments (e.g., Cornell and Schwertmann, 2003).

508 Finally, our experiments and their model-based interpretation also show that the accurate and independent 509 determination of key transport parameters (i.e., pore diffusion coefficient in the 1-D setups and the 510 transverse dispersion coefficient in the 2-D flow-through system) as well as the detailed study and 511 description of reaction kinetics allows the predictive use of numerical simulations for reactive systems 512 where transport and reactive processes are coupled.

\section{Acknowledgments}

515 This study was funded by the DFG (German Research Foundation) through the Research Group FOR 831

516 'Dynamic Capillary Fringes - A Multidisciplinary Approach' (grant GR971/22-1) and by the Baden517 Württemberg Stiftung through the Elite Program for Postdocs. M.R. acknowledges the support of the 518 Marie Curie International Outgoing Fellowship (DILREACT project) within the $7^{\text {th }}$ European Community 519 Framework Program. The authors thank Wolfgang Kürner, Bernice Nisch, Ye Yu, and the 520 Geomicrobiology Group at the University of Tübingen (Department of Geosciences) for technical support and Prof. S.B. Haderlein for helpful discussions.

\section{REFERENCES}

Appelo, C.A.J., B. Drijver, R. Hekkenberg, and M. de Jonge. 1999. Modeling in situ iron removal from ground water. Ground Water 37(6):811-817.

Appelo, C.A.J., and D. Postma. 2005. Geochemistry, groundwater and pollution. $2^{\text {nd }}$ ed. CRC Press.

Barber, C., and G.B. Davis. 1987. Volatilization of methane from groundwater: Laboratory simulation and field investigations in a sand aquifer. In: Proceedings AWRC Conference "Groundwater Systems under Stress", Brisbane, Australia. AWRC Conference Series 13:157-164. 
Bauer, R.D., M. Rolle, P. Kürzinger, P. Grathwohl, R.U. Meckenstock, and C. Griebler. 2009. Two-dimensional flow-through microcosms - versatile test systems to study biodegradation processes in porous aquifers. J. Hydrol. 369:284-295. doi:10.1016/j.jhydrol.2009.02.037.

Bear, J., and Y. Bachmat. 1967. A generalized theory on hydrodynamic dispersion in porous media. In: IASH symposium on artificial recharge and management of aquifers, Haifa, Israel 72:7-16.

Boudreau, B.P. 1996. The diffusive tortuosity of fine-grained unlithified sediments. Geochim. Cosmochim. Ac.

Boving, T., and P. Grathwohl. 2001. Tracer diffusion coefficients in sedimentary rocks: Correlation to porosity and 60(16):3139-3142.

544 Chapelle, F.H. 2001. Ground-water microbiology and geochemistry. $2^{\text {nd }}$ ed. John Wiley \& Sons, New York.

545 Charlton, S. R., and D.L. Parkhurst. 2011. Modules based on the geochemical model PHREEQC for use in scripting

Bruggeman, D.A.G. 1935. Berechnung verschiedener physikalischer Konstanten von heterogenen Substanzen. I. Dielektrizitätskonstanten und Leitfähigkeiten der Mischkörper aus isotropen Substanzen. Ann. Ph. Leipzig. 416(7):636-664. and programming languages. Comput. Geosci. 37(10):1653-1663. doi:10.1016/j.cageo.2011.02.005.

Chiogna, G., C. Eberhardt, P. Grathwohl, O.A. Cirpka, and M. Rolle. 2010. Evidence of compound-dependent hydrodynamic and mechanical transverse dispersion by multitracer laboratory experiments. Env. Sci. Technol. 44(2):688-693. doi:10:1021/es9023964.

Chiogna, G., O.A. Cirpka, P. Grathwohl, and M. Rolle. 2011. Relevance of local compound-specific transverse dispersion for conservative and reactive mixing in heterogeneous porous media. Water Resour. Res. 47:W07540. doi:10.1029/2010WR010270.

Chiogna, G., D.L. Hochstetler, A. Bellin, P.K. Kitanidis, and M. Rolle. 2012. Mixing, entropy and reactive solute transport. Geophys. Res. Lett. 39:L20405. doi:10.1029/2012GL053295.

Clennel, M.B. 1997. Tortuosity: A guide through the maze. In: Developments in Petrophysics. Ed. Lovell, M.A., and P.K. Harvey. Geol. Soc. Special Publication 122:299-344.

Cornell, R.M., and U. Schwertmann. 2003. The iron oxides: Structure, properties, reactions, occurences and uses. $2^{\text {nd }}$

559 Coutelieris, F.A., and J.M.P.Q. Delgado. 2012. Transport processes in porous media. Springer, ISBN 978-3-64227909-6. 
Davison, W., and G. Seed. 1983. The kinetics of the oxidation of ferrous iron in synthetic and natural waters. Geochim. Cosmochim. Ac. 47:67-79.

563 Delgado, J.M.P.Q. 2006. A simple experimental technique to measure tortuosity in packed beds. Can. J. Chem. Eng. 84:651-655.

Dobson, R., M.H. Schroth, J. Zeyer. 2007. Effect of water-table fluctuations on dissolution and biodegradation of a multi-component, light nonaqueous-phase liquid. J. Contam. Hydrol. 94:235-248.

Epstein, N. 1989. On the tortuosity and the tortuosity factor in flow and diffusion through porous media. Chem. Eng. Sci. 44(3):777-779.

Farnsworth, C.E., A. Voegelin, and J.G. Hering. 2012. Manganese oxidation induced by water table fluctuations in a sand column. Env. Sci. Technol. 46:277-284.

Franken, G., D. Postma, W.H.M. Duijisveld, J. Böttcher, and J. Molson. 2009. Acid groundwater in an anoxic aquifer: Reactive transport modelling of buffering processes. Appl. Geochem. 24:890-899.

573 Freitas, J.G., B. Doulatyari, J.W. Molson, J.F. Barker. 2011. Oxygenated gasoline release in the unsaturated zone, Part 2: Downgradient transport of ethanol and hydrocarbons. J. Contam. Hydrol. 125:70-85. doi:10.1016/j.jconhyd.2011.05.002.

Frini, A., and E. Maaoui. 1997. Kinetics of the formation of goethite in the presence of sulfates and chlorides of monovalent cations. J. Colloid Interface Sci. 190:269-277.

578 Gebrehiwet, T., L. Guo, D. Fox, Y. Fujita, R. Smith, J. Henriksen, and G. Redden. 2014. Precipitation of calcium carbonate and calcium phosphate under diffusion controlled mixing. Appl. Geochem. 46:43-56.

Good, N.E., G.D. Winget, W. Winter, T.N. Connolly, S. Izawa, and R.M.M. Singh. 1966. Hydrogen ion buffers for biological research. Biochemistry 5(2):467-477.

Grathwohl, P. 1998. Diffusion in natural porous media: Contaminant transport, sorption/desorption and dissolution kinetics. Springer, ISBN 0-792-38102-5.

Haberer, C.M., M. Rolle, S. Liu, O.A. Cirpka, and P. Grathwohl. 2011. A high-resolution non-invasive approach to quantify oxygen transport across the capillary fringe and within the underlying groundwater. J. Contam. Hydrol. 122:26-39.

Haberer, C.M., M. Rolle, O.A. Cirpka, and P. Grathwohl. 2012. Oxygen transfer in a fluctuating capillary fringe. Vadose Zone J. doi.10.2136/vzj2011.0056. 
Haberer, C.M., O.A. Cirpka, M. Rolle, and P. Grathwohl. 2014a. Experimental sensitivity analysis of oxygen transfer in the capillary fringe. Ground Water 52(1):37-49. doi:10.1111/gwat.12028.

591 Haberer, C.M., M. Rolle, O.A. Cirpka, and P. Grathwohl. 2014b. Impact of heterogeneity on oxygen transfer in a fluctuating capillary fringe. Ground Water - in press. doi:10.1111/gwat.12149.

Harbaugh, A.W. 2005. MODFLOW-2005, the U.S. Geological Survey modular ground-water model - The GroundWater Flow Process. U.S. Geological Survey Techniques and Methods 6-A16. Reston, Virginia: USGS.

Hochstetler, D.L., M. Rolle, G. Chiogna, C.M. Haberer, P. Grathwohl, and P. Kitanidis. 2013. Effects of compoundspecific transverse mixing on steady-state reactive plumes: Insights from pore-scale simulations and Darcyscaly experiments. Adv. Wat. Resour. 54:1-10.

$598 \mathrm{Hu}$, Q., and J.S.Y. Wang. 2003. Aqueous-phase diffusion in unsaturated geologic media: A review. Critical Reviews in Env. Sci. Technol. 33(3):275-297.

600 Jost, D., C.M. Haberer, P. Grathwohl, J. Winter, and C. Gallert. 2014. Oxygen transfer in a fluctuating capillary 601 fringe: Impact of microbial respiratory activity. Vadose Zone J. - submitted.

602 Kitanidis, P. 1994. The concept of the dilution index. Water Resour. Res. 30(7):2011-2026. 603 doi:10.1029/94WR00762.

604 Kjøller, C., D. Postma, and F. Larsen. 2004. Groundwater acidification and the mobilization of trace metals in a 605 sandy aquifer. Env. Sci. Technol., 38(10):2829-2835.

606 Klenk, I.D., and P. Grathwohl. 2002. Transverse vertical dispersion in groundwater and the capillary fringe. J. 607 Contam. Hydrol. 58:111-128.

608 Liu, S., R. Liedl, and P. Grathwohl. 2010. Simple analytical solutions for oxygen transfer into anaerobic 609 groundwater. Water Resour. Res. 46:W10542. doi:10.1029/2009WR008434.

610 Mächler, L., S. Peter, M.S. Brennwald, and R. Kipfer. 2013. Excess air formation as a mechanism for delivering 611 oxygen to groundwater. Water Resour. Res. 49:6847-6856. doi:10.1002/wrcr.20547.

612 Maier, U., H. Rügner, and P. Grathwohl. 2007. Gradients controlling natural attenuation of ammonium. Appl. 613 Geochem. 22:2606-2617. doi:10.1016/j.apgeochem.2007.06.009.

614 Martin, S.T. 2005. Precipitation and dissolution of iron and manganese oxides. In: Environmental catalysis. Ed. 615 Grassian, V.H. CRC Press Boca Raton, 61-81.

616 McCarthy, K.A., and R.L. Johnson. 1993. Transport of volatile organic compounds across the capillary fringe. Water 617 Resour. Res. 29(6):1675-1683. 
618 Millero, F.J., S. Sotolongo, and M. Izaguirre. 1987. The oxidation kinetics of Fe(II) in seawater. Geochim. 619 Cosmochim. Ac. 51:793-801.

620 Molins, S., D. Trebotich, C. Steefel, and C. Shen. 2012. An investigation of the effect of pore scale flow on average 621 geochemical reaction rates using direct numerical simulation. Water Resour. Res. 48:W03527. doi:10.1029/2011WR011404.

623 Morgan, B., and O. Lahav. 2007. The effect of $\mathrm{pH}$ on the kinetics of spontaneous Fe(II) oxidation by $\mathrm{O}_{2}$ in aqueous solution: Basic principles and a simple heuristic description. Chemosphere 68:2080-2084.

625 Muniruzzaman, M., C.M. Haberer, P. Grathwohl, and M. Rolle. 2014. Multicomponent ionic dispersion during 626 transport of electrolytes in heterogeneous porous media: Experiments and model-based interpretation. Geochim. Cosmochim. Ac. doi:10.1016/j.gca.2014.06.020.

Park, B., and B.A. Dempsey. 2005. Heterogeneous oxidation of Fe(II) on ferric oxide at neutral pH and a low partial pressure of $\mathrm{O}_{2}$. Env. Sci. Technol. 39(17):6494-6500.

Parkhurst, D.L., and C.A.J. Appelo. 2013. Description of input and examples for PHREEQC version 3 - A computer program for speciation, batch-reaction, one-dimensional transport, and inverse geochemical calculations. U.S.

Peng, S., Q. Hu, and S. Hamamoto. 2012. Diffusivity of rocks: Gas diffusion measurements and correlation to porosity and pore size distribution. Water Resour. Res. 48:W02507. doi:10.1029/2011WR011098.

636 Pollock, D.W. 1994. A particle tracking post-processing package for MODFLOW: The U.S. Geological Survey finite-difference ground-water flow model. User's guide for modpath/modpath-plot, version 3. of 94-464, U.S. Geol. Survey, Reston, VA.

Prommer, H., D.A. Barry, and C. Zheng. 2003. MODFLOW/MT3DMS-based reactive multicomponent transport

641 Prommer, H., and P.J. Stuyfzand. 2005. Identification of temperature-dependent water quality changes during a deep 642 well injection experiment in a pyritic aquifer. Environ. Sci. Technol. 39(7):2200-2209.

643 Prommer, H., B. Anneser, M. Rolle, F. Einsiedl, and C. Griebler. 2009. Biogeochemical and isotopic gradients in a 644 BTEX/PAH contaminant plume: model-based interpretation of a high-resolution field data set. Environ. Sci. 645 Technol. 43:8206-8212. doi:10.1021/es901142a. 

in porous media with in situ generation of reactants. Environ. Sci. Technol. 48(1):542-549.

648 Rezanezhad, F., R.-M. Couture, R. Kovac, D. O’Connell, and P. Van Capellen. 2014. Water table fluctuations and soil biogeochemistry: An experimental approach using an automated soil column system. J. Hydrol. 509:245256.

Rolle, M., D. Hochstetler, G. Chiogna, P.K. Kitanidis, and P. Grathwohl. 2012. Experimental investigation and porescale modeling interpretation of compound-specific transverse dispersion in porous media. Transp. Porous Med. 93:347-362. doi:10.1007/s11242-012-9953-8.

654 Rolle, M., Md. Muniruzzaman, C.M. Haberer, and P. Grathwohl. 2013a. Coulombic effects in advection-dominated transport of electrolytes in porous media: Multicomponent ionic dispersion. Geochim. Cosmochim. Ac. 120:195-205.

Rolle, M., G. Chiogna, D.L. Hochstetler, and P.K. Kitanidis. 2013b. On the importance of diffusion and compoundspecific mixing for groundwater transport: An investigation from pore to field scale. J. Contam. Hydrol. 153:51-68. doi:10.1016/j.jconhyd.2013.07.006.

Rolle, M., and P.K. Kitanidis, 2014. Effects of compound-specific dilution on transient transport and solute breakthrough: A pore-scale analysis. Adv. Water Resour. doi:10.1016/j.advwatres.2014.06.012.

Sabatini, D.A. 2000. Sorption and intraparticle diffusion of fluorescent dyes with consolidated aquifer media. Ground Water 38(5):651-656.

Schmidt, C., L. Corbari, F. Gaill, and N. Le Bris. 2009. Biotic and abiotic controls on iron oxyhydroxide formation in the gill chamber of the hydrothermal vent shrimp Rimicaris exoculata. Geobiology 7:454-464.

666 Shackelford, C.D. 1991. Laboratory diffusion testing for waste disposal - A review. J. Contam. Hydrol. 7:177-217.

667 Sharma, P., M. Rolle, B. Kocar, S. Fendorf, and A. Kappler. 2011. Influence of natural organic matter on arsenic transport and retention. Env. Sci. Technol. 45:546-553.

669 Smedley, P.L., and D.G. Kinniburgh. 2002. A review of the source, behavior and distribution of arsenic in natural $670 \quad$ waters. Appl. Geochem. 17:517-568.

671 Sobolev, D., and E.E. Roden. 2001. Suboxic deposition of ferric iron by bacteria in opposing gradients of Fe(II) and 672 oxygen at circumneutral pH. Appl. Environ. Microb. 67(3):1328-1334. doi:10.1128/AEM.67.3.13281334.2001. 
Stollenwerk, K.G. 2003. Geochemical processes controlling transport of arsenic in groundwater: A review of adsorption. In: Arsenic in Groundwater. Ed. Welch, A.H., and K.G. Stollenwerk. Kluwer Academic Publishers Boston, 67-100.

678 Stumm, W., and G.F. Lee. 1961. Oxygenation of ferrous iron. Ind. Eng. Chem. 53:143-146.

679 Stumm, W., and J.J. Morgan. 1996. Aquatic chemistry: chemical equilibria and rates in natural waters. Jon Wiley and Sons, New York.

Sung, W., and J.J. Morgan. 1980. Kinetics and product of ferrous iron oxygenation in aqueous systems. Env. Sci. Technol. 14(5):561-568.

Tartakovsky, A.M., G.D. Redden, P.C. Lichtner, T.C. Scheibe, and P. Meakin. 2008. Mixing-induced precipitation: Experimental study and multi-scale numerical analysis. Water Resour. Res. 44:W06S04. doi:10.1029/2006WR005725.

Vencelides, Z., O. Sracek, and H. Prommer. 2007. Iron cycling and its impact on the electron balance at a petroleum hydrocarbon contaminated site in Hnevice, Czech Republic. J. Contam. Hydrol. 89:270-294.

Viollier, E., P.W. Inglett, K. Hunter, A.N. Roychoudhury, and P. Van Cappellen. 2000. The ferrozine method revisited: $\mathrm{Fe}(\mathrm{II}) / \mathrm{Fe}(\mathrm{III})$ determination in natural waters. Appl. Geochem. 15:785-790.

Voegelin, A., R. Kaegi, J. Frommer, D. Vantelon, and S.J. Hug. 2010. Effect of phosphate, silicate, and Ca on

Voegelin, A., R. Kaegi, M. Berg, K. Nitzsche, A. Kappler, V. Lan, P. Trang, J. Goettlicher, and R. Steininger. 2014. $\mathrm{Fe}(\mathrm{III})$-precipitates formed in aerated $\mathrm{Fe}(\mathrm{II})$ - and As(III)-containing water studied by X-ray absorption

Wallis, I., H. Prommer, T. Pichler, V.E.A. Post, S. Norton, M. Annable, and C.T. Simmons. 2011. A process-based reactive transport model to quantify arsenic mobility during aquifer storage and recovery of potable water. Environ. Sci. Technol. 45(16):6924-6931.

Werner, D., and P. Höhener. 2002. The influence of water table fluctuations on the volatilization of contaminants from groundwater. In: Groundwater quality: Natural and enhanced restoration of groundwater pollution: Proceedings of GQ 2001, Sheffield, UK. June 2001. Ed. Thornton, S.F., and S.E. Oswald. IAHS Publ. 275. Int. Assoc. Hydrol Sci., Wallingford, UK. p. 213-218. 
703

704

705

706

707

708

709

710

711

712

713

714

715

716

717

718

719

720

Williams, M.D., and M. Oostrom, 2000. Oxygenation of anoxic water in a fluctuating water table system: An experiment and numerical study. J. Hydrol. 230:70-85.

Wissmeier, L., and D.A. Barry. 2011. Simulation tool for variably saturated flow with comprehensive geochemical reactions in two- and three-dimensional domains. Environ. Modell. Softw. 26(2):210-218. doi:10.1016/j.envsoft.2010.07.005.

Wolthoorn, A., E.J.M. Temminghoff, L. Weng, and W.H. van Riemsdijk. 2004. Colloid formation in groundwater: Effect of phosphate, manganese, silicate and dissolved organic matter on the dynamic heterogeneous oxidation of ferrous iron. Appl. Geochem. 19:611-622.

Yoon H., A.J. Valocchi, C.J. Werth, and T. Dewers. 2012. Pore-scale simulation of mixing-induced calcium carbonate precipitation and dissolution in a microfluidic pore network. Water Resour. Res. 48(2):W02524. doi:10.1029/2011WR011192.

Zhang C., K. Dehoff, N. Hess, M. Oostrom, T.W. Wietsma, A.J. Valocchi, B.W. Fouke, and C.J. Werth. 2010. Porescale study of transverse mixing induced $\mathrm{CaCO}_{3}$ precipitation and permeability reduction in a model subsurface sedimentary system. Environ. Sci. Technol. 44:7833-7838. doi:10.1021/es1019788.

Zheng, C., and P.P. Wang. 1999. MT3DMS: A modular three-dimensional multispecies model for simulation of advection, dispersion, and chemical reactions of contaminants in groundwater systems. Documentation and user's guide. Contract report SERDP-99-1. U.S. Army Engineer Research and Development Center, Vicksburg, MS. 
Fig. 1: Experimental setups used in this study: Batch experiments, 1-D diffusion experiments, and 2-D flow-through experiments.

Fig. 2: Photograph of the experimental setup used to perform the 1-D diffusion experiments (right panel) and schematics of system operation in different experimental phases, i.e., flow-through mode before starting the experiment (to achieve constant background concentrations) vs. no-flow conditions during the experiment (oxygen is allowed to diffuse into the system).

729

Fig. 3: Normalized iron(II)-concentration vs. time in the batch experiments performed (Table 1). Batch A: pH 7 (not buffered), Batch B: pH 7 (buffered), Batch C: pH 8 (buffered), Batch D: pH 7 (buffered) and with catalyzer.

Fig. 4: Observed and simulated evolution of (a) iron(II), (b) oxygen, and (c) $\mathrm{pH}$ in the Batch B experiment.

Fig. 5: Oxygen concentration profiles in the conservative 1-D diffusion experiment using glass beads as porous medium: (a) Spatial profiles measured at increasing times (i.e., in 3 to 6 hour-time intervals) along the oxygensensitive sensor strip. The depth $=0 \mathrm{~mm}$ indicates the location of the unsaturated/saturated interface. (b) Oxygen breakthrough curve at $13 \mathrm{~mm}$ depth below the interface between the atmosphere and the fully water-saturated porous medium (symbols indicate the experimental data and are shown at lower temporal resolution than the actual measurements, performed every $10 \mathrm{~s})$.

Fig. 6: Spatial oxygen concentration profiles in the 1-D diffusion experiments: (a) Conservative case, (b) reactive

743 case with kinetic iron(II) oxidation, and (c) instantaneous reaction. The depth of $0 \mathrm{~mm}$ indicates the location of the 744 unsaturated/saturated interface.

746 Fig. 7: Diffusive oxygen fronts propagating in a pH-buffered porous medium over time: (a) Penetration depths for $747 C_{n o r m}=0.05$ and (b) velocity of the propagating oxygen fronts. 
749 Fig. 8: Temporal oxygen concentration profiles in the 1-D diffusion experiments (detected at $13 \mathrm{~mm}$ depth below the 750 interface between the atmosphere and the saturated porous medium) for the conservative, reactive kinetic, and 751 reactive instantaneous cases.

752

753 Fig. 9: Long-term propagation of oxygen concentration fronts in 1-D diffusive systems. Spatial profiles at (a) 0.5 754 days and 5.0 days, and at (b) 50 days and 500 days.

755

756 Fig. 10: 2-D flow-through experiment: (a) Photograph of the experimental setup during the reactive phase of the 757 experiment (with kinetic iron(II) oxidation and buffered $\mathrm{pH}$ ), (b) simulated flow lines using MODPATH (Pollock, 758 1994) and color map showing the simulated precipitation of ferrihydrite (with maximum concentration close to the 759 inlet: $2.97 \times 10^{-4} \mathrm{~mol} \mathrm{~L}^{-1}$ of bulk volume at 0.2 days). The vertical orange line shows the location of the vertical 760 oxygen-sensitive polymer strip $(x=13 \mathrm{~cm})$. (c) Concentration profiles for the conservative and reactive experiments 761 (the $y$-axis represents the distance from the upper boundary of the flow-through setup).

762

763 Fig. 11: Penetration depth (a) and velocity of propagation of the dispersive oxygen fronts (b) in the quasi 2-D flow764 through setup as function of the longitudinal distance from the inlet of the flow-through chamber for two seepage 765 velocities ( $v=1.9$ and $0.19 \mathrm{~m} \mathrm{~d}^{-1}$, respectively). 
Table 1. Overview of the batch experiments.

\begin{tabular}{ccccc}
\hline Batch & Ferrous Iron, $\mathbf{c}\left(\mathbf{F e}^{2+}\right)$ & Initial pH [-] & pH-buffer, c(PIPES $)$ & Catalyzer, $\mathbf{c}\left(\mathbf{C u}^{2+}\right)$ \\
\hline A & $1.79 \times 10^{-4} \mathrm{~mol} \mathrm{~L}^{-1}$ & 7 & - & - \\
B & $1.79 \times 10^{-4} \mathrm{~mol} \mathrm{~L}^{-1}$ & 7 & $1 \times 10^{-3} \mathrm{~mol} \mathrm{~L}^{-1}$ & - \\
C & $1.79 \times 10^{-4} \mathrm{~mol} \mathrm{~L}^{-1}$ & 8 & $1 \times 10^{-3} \mathrm{~mol} \mathrm{~L}^{-1}$ & - \\
D & $1.79 \times 10^{-4} \mathrm{~mol} \mathrm{~L}^{-1}$ & 7 & $1 \times 10^{-3} \mathrm{~mol} \mathrm{~L}^{-1}$ & $3 \times 10^{-7} \mathrm{~mol} \mathrm{~L}^{-1}$ \\
\hline
\end{tabular}

767 
768 Table 2. Summary of porous medium properties and flow and transport parameters in the 2-D setup.

\begin{tabular}{ll}
\hline Parameter & Value \\
\hline Inner dimensions of the flow-through chamber, $L \times H \times W[\mathrm{~cm}]$ & $16.2 \times 12.7 \times 0.5$ \\
Average grain diameter [mm] & 0.50 \\
Porosity of the porous medium [\%] & 39.7 \\
Flow rate, $Q\left[\mathrm{~m}^{3} \mathrm{~s}^{-1}\right]$ & $5.63 \times 10^{-9}$ \\
Cross-sectional flow-through area $\left[\mathrm{m}^{2}\right]$ & $5.93 \times 10^{-4}$ \\
Hydraulic conductivity, $\boldsymbol{K}\left[\mathrm{m} \mathrm{s}^{-1}\right]$ & $2.5 \times 10^{-3}$ \\
Aqueous diffusion coefficient for oxygen, $D_{a q}\left[\mathrm{~m}^{2} \mathrm{~s}^{-1}\right]\left(\right.$ at $\left.22^{\circ} \mathrm{C}\right)$ & $1.97 \times 10^{-9}$ \\
\hline
\end{tabular}

769 
Table 3. Summary of parameters and results for the conservative experiments in the 1-D setup.

\begin{tabular}{lcc}
\hline Porous medium & Glass beads & River Rhine sand \\
\hline $\boldsymbol{D}_{\boldsymbol{p}}\left[\mathbf{m}^{\mathbf{2}} \mathbf{s}^{-1}\right]$ & $1.18 \times 10^{-9}$ & $1.14 \times 10^{-9}$ \\
$\boldsymbol{\tau}(\mathbf{d i f f u s i o n})[-]$ & 1.67 & 1.73 \\
$\boldsymbol{\tau}(\boldsymbol{\varepsilon}, \boldsymbol{m}=\mathbf{1 . 5})[-]$ & 1.57 & 1.52 \\
$\boldsymbol{\varepsilon}$ (porosity) [\%] & 40.6 & 43.5 \\
\hline
\end{tabular}




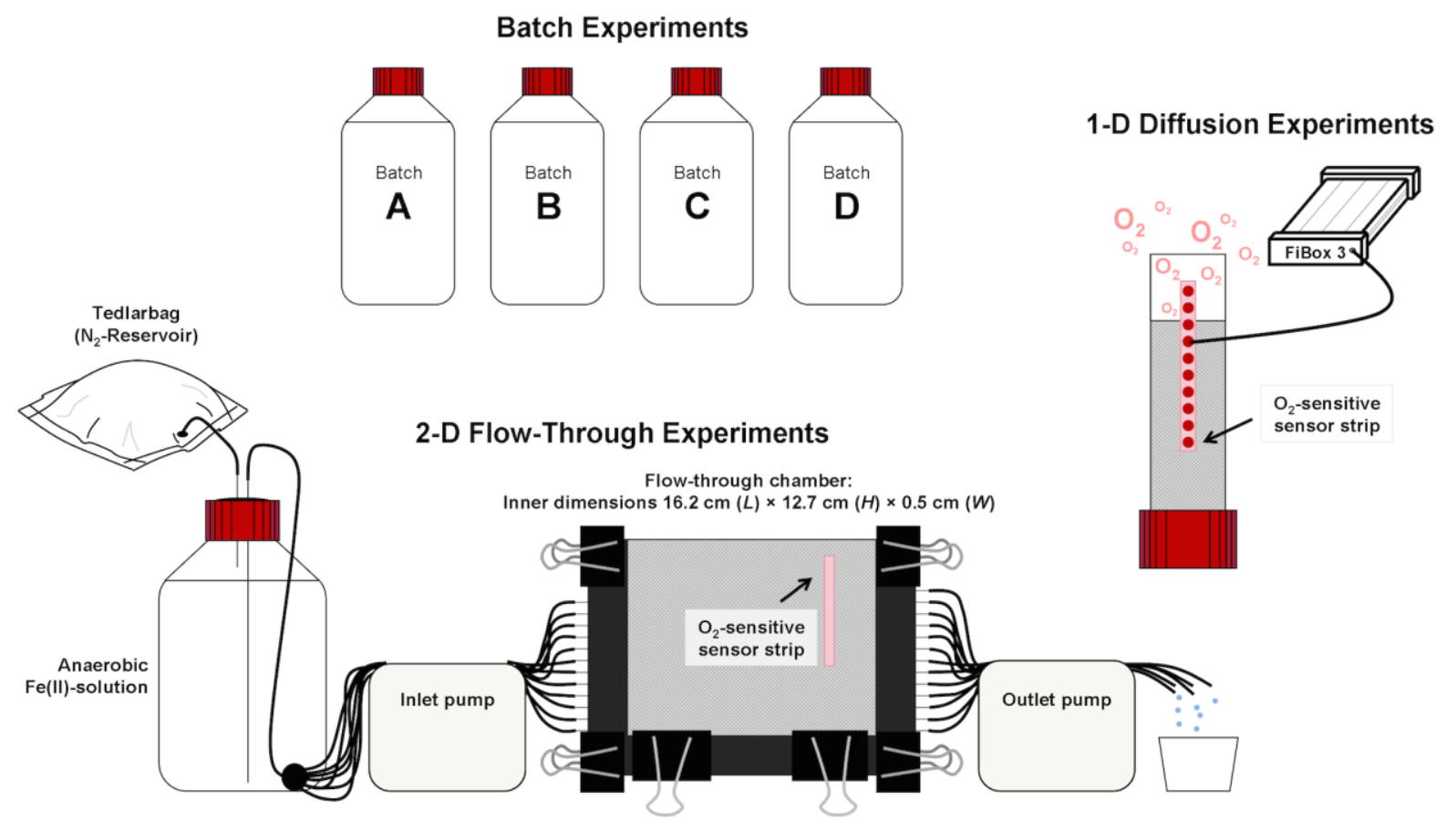

772 Fig. 1: Experimental setups used in this study: Batch experiments, 1-D diffusion experiments, and 2-D flow-through 773 experiments. 

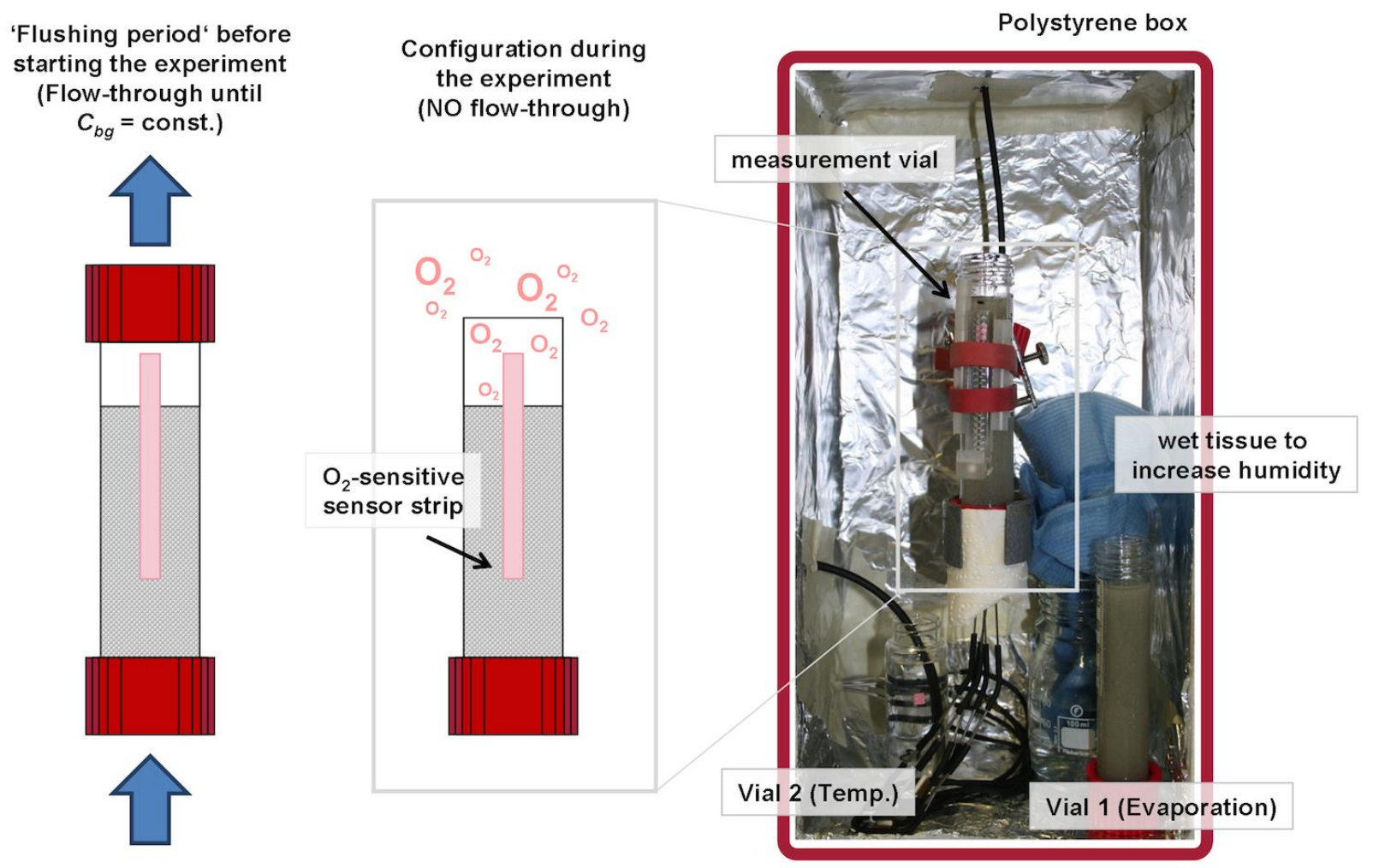

775 Fig. 2: Photograph of the experimental setup used to perform the 1-D diffusion experiments (right panel) and 776 schematics of system operation in different experimental phases, i.e., flow-through mode before starting the

777 experiment (to achieve constant background concentrations) vs. no-flow conditions during the experiment (oxygen is 778 allowed to diffuse into the system). 


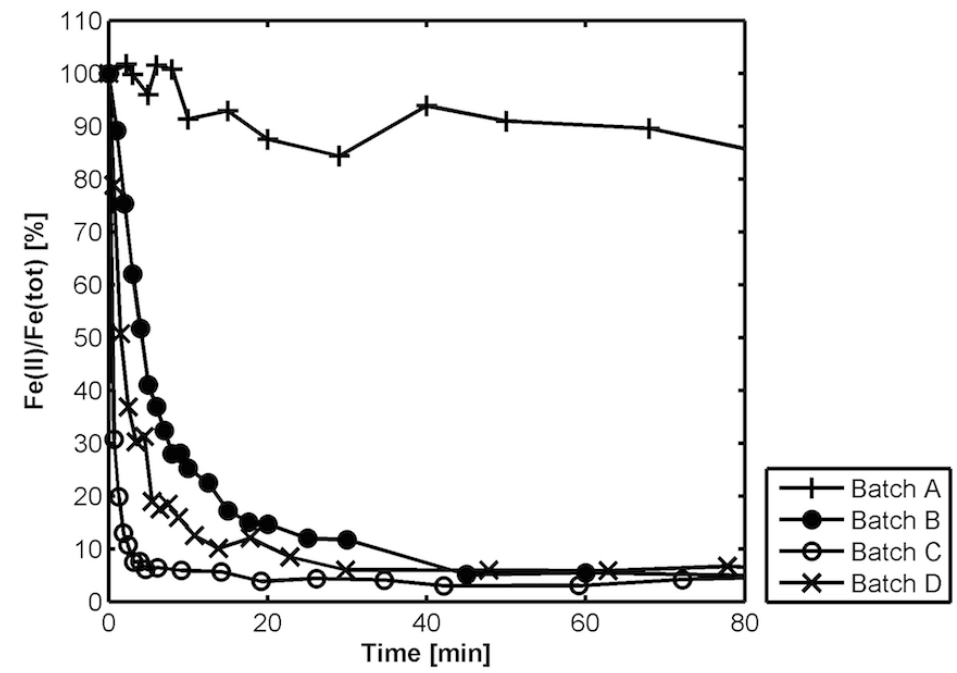

780 Fig. 3: Normalized iron(II)-concentration vs. time in the batch experiments performed (Table 1). Batch A: pH 7 (not

781 buffered), Batch B: pH 7 (buffered), Batch C: pH 8 (buffered), Batch D: pH 7 (buffered) and with catalyzer. 

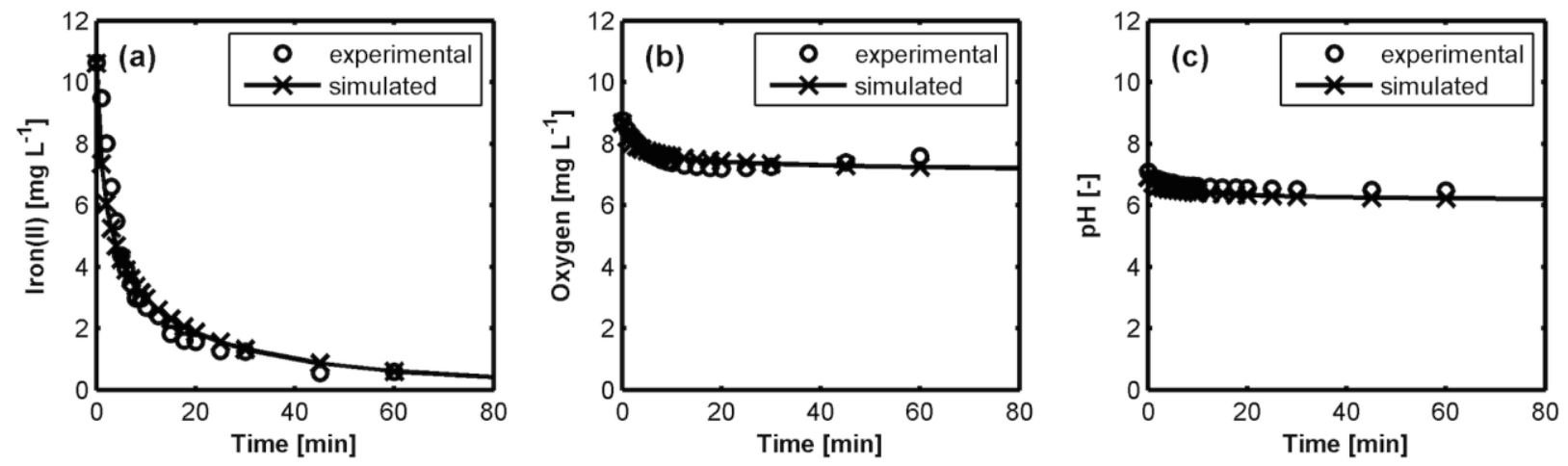

783 Fig. 4: Observed and simulated evolution of (a) iron(II), (b) oxygen, and (c) pH in the Batch B experiment. 

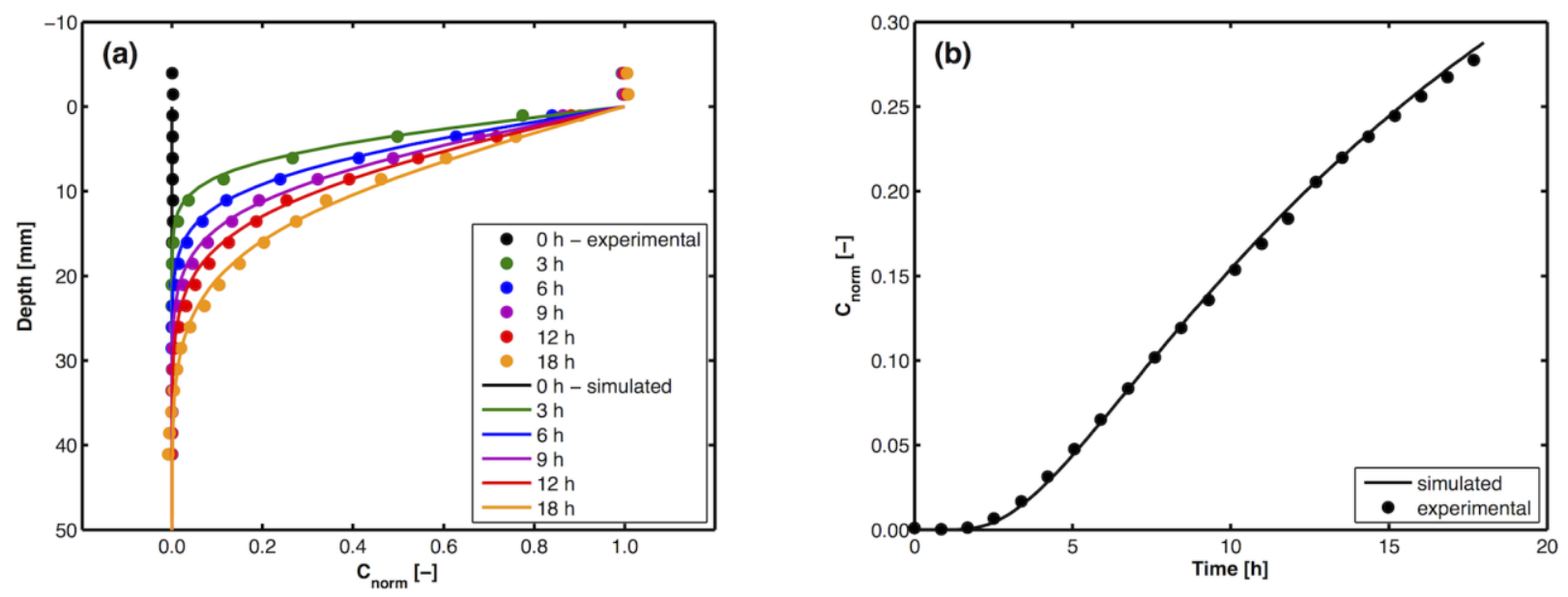

785 Fig. 5: Oxygen concentration profiles in the conservative 1-D diffusion experiment using glass beads as porous

786 medium: (a) Spatial profiles measured at increasing times (i.e., in 3 to 6 hour-time intervals) along the oxygen-

787 sensitive sensor strip. The depth $=0 \mathrm{~mm}$ indicates the location of the unsaturated/saturated interface. (b) Oxygen

788 breakthrough curve at $13 \mathrm{~mm}$ depth below the interface between the atmosphere and the fully water-saturated porous

789 medium (symbols indicate the experimental data and are shown at lower temporal resolution than the actual

790 measurements, performed every $10 \mathrm{~s}$ ). 
(a) CONSERVATIVE

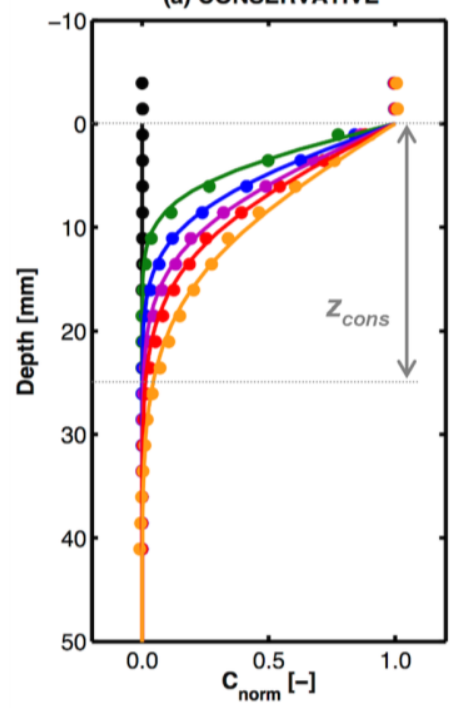

(b) REACTIVE (kinetic)

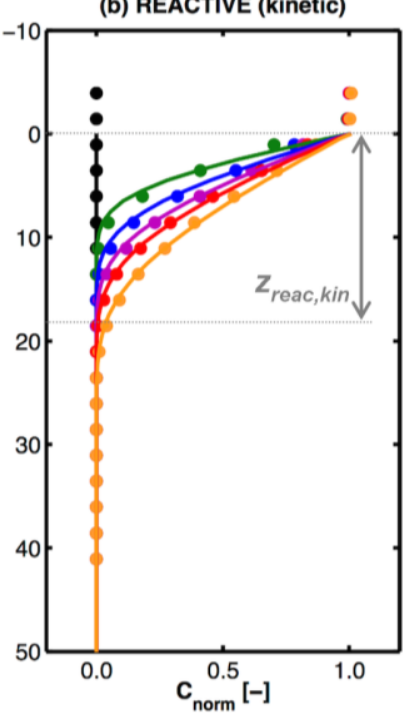

(c) REACTIVE (instantaneous)

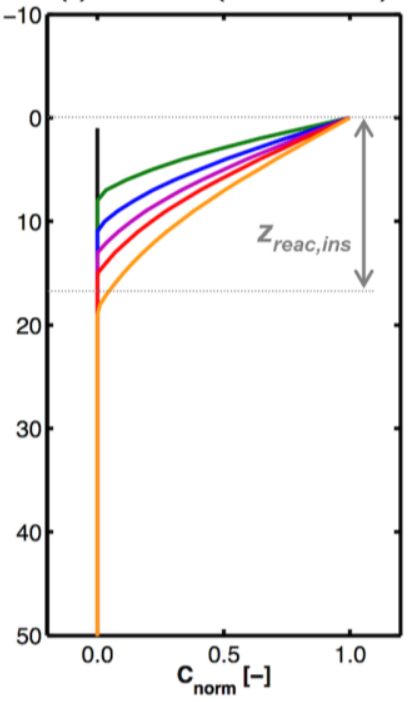

- $0 \mathrm{~h}$ - experimental

- $3 \mathrm{~h}$

- $6 \mathrm{~h}$

- $9 \mathrm{~h}$

- $12 \mathrm{~h}$

$18 \mathrm{~h}$

- $0 \mathrm{~h}$ - simulated

$3 \mathrm{~h}$

$9 \mathrm{~h}$

$-12 \mathrm{~h}$
$-18 \mathrm{~h}$

792 Fig. 6: Spatial oxygen concentration profiles in the 1-D diffusion experiments: (a) Conservative case, (b) reactive

793 case with kinetic iron(II) oxidation, and (c) instantaneous reaction. The depth of $0 \mathrm{~mm}$ indicates the location of the

794 unsaturated/saturated interface. 

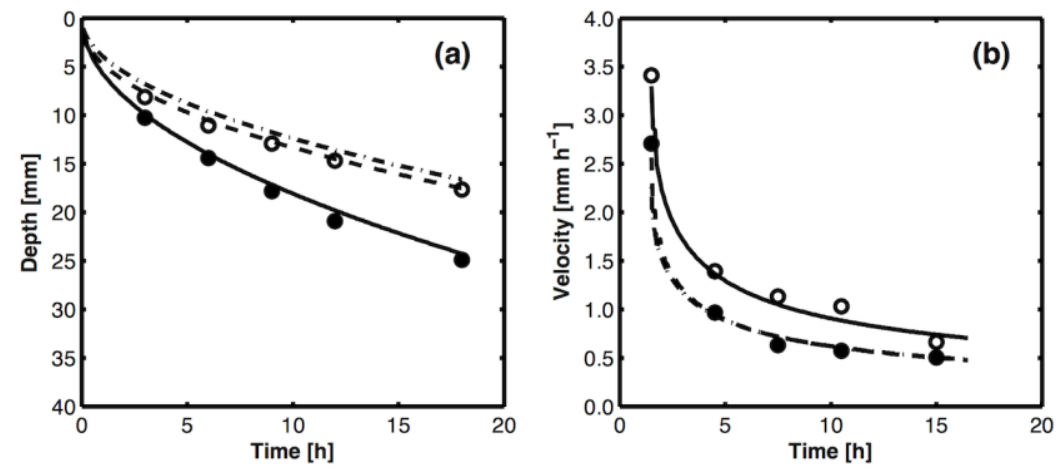
- conservative, experimental
conservative, simulated
- reactive (kinetic, $\mathrm{pH}$ buffered), experimental
- - - reactive (kinetic, pH buffered), simulated
. - - ' reactive (instantaneous), simulated

796 Fig. 7: Diffusive oxygen fronts propagating in a pH-buffered porous medium over time: (a) Penetration depths for $797 C_{\text {norm }}=0.05$ and (b) velocity of the propagating oxygen fronts. 


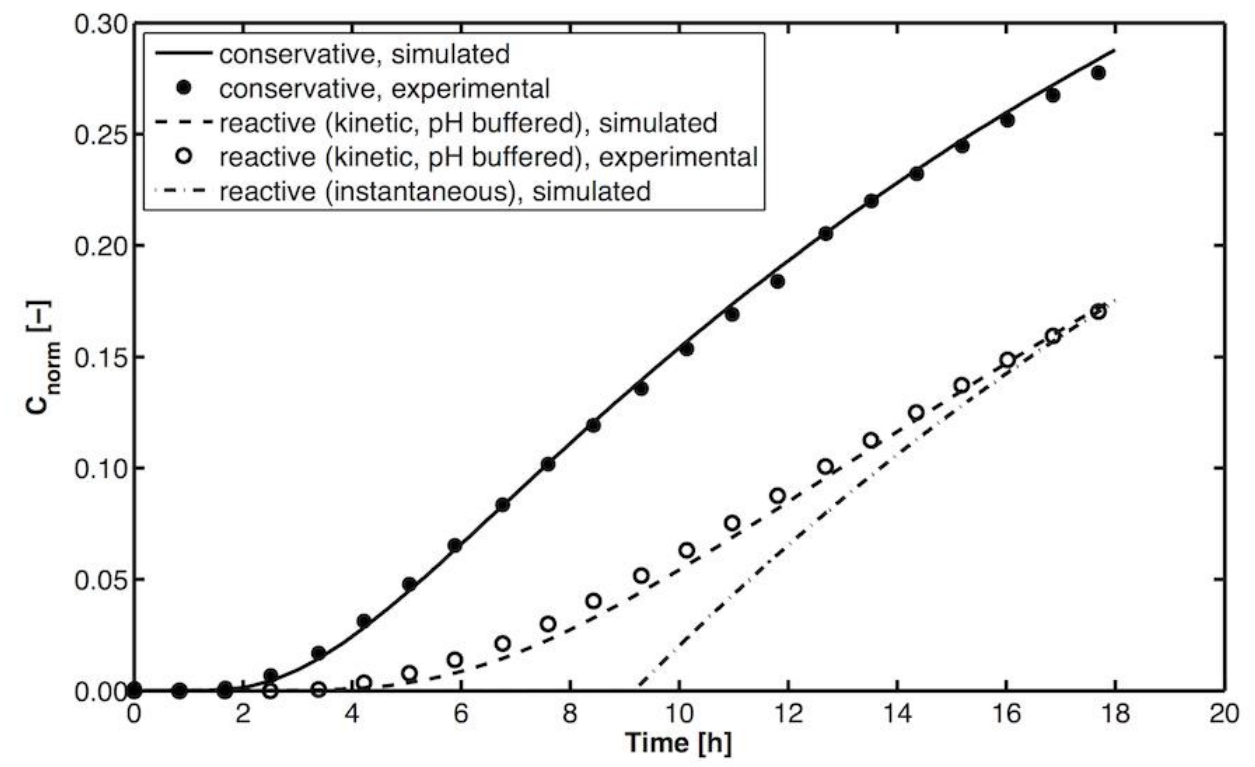

799 Fig. 8: Temporal oxygen concentration profiles in the 1-D diffusion experiments (detected at $13 \mathrm{~mm}$ depth below the 800 interface between the atmosphere and the saturated porous medium) for the conservative, reactive kinetic, and reactive instantaneous cases. 

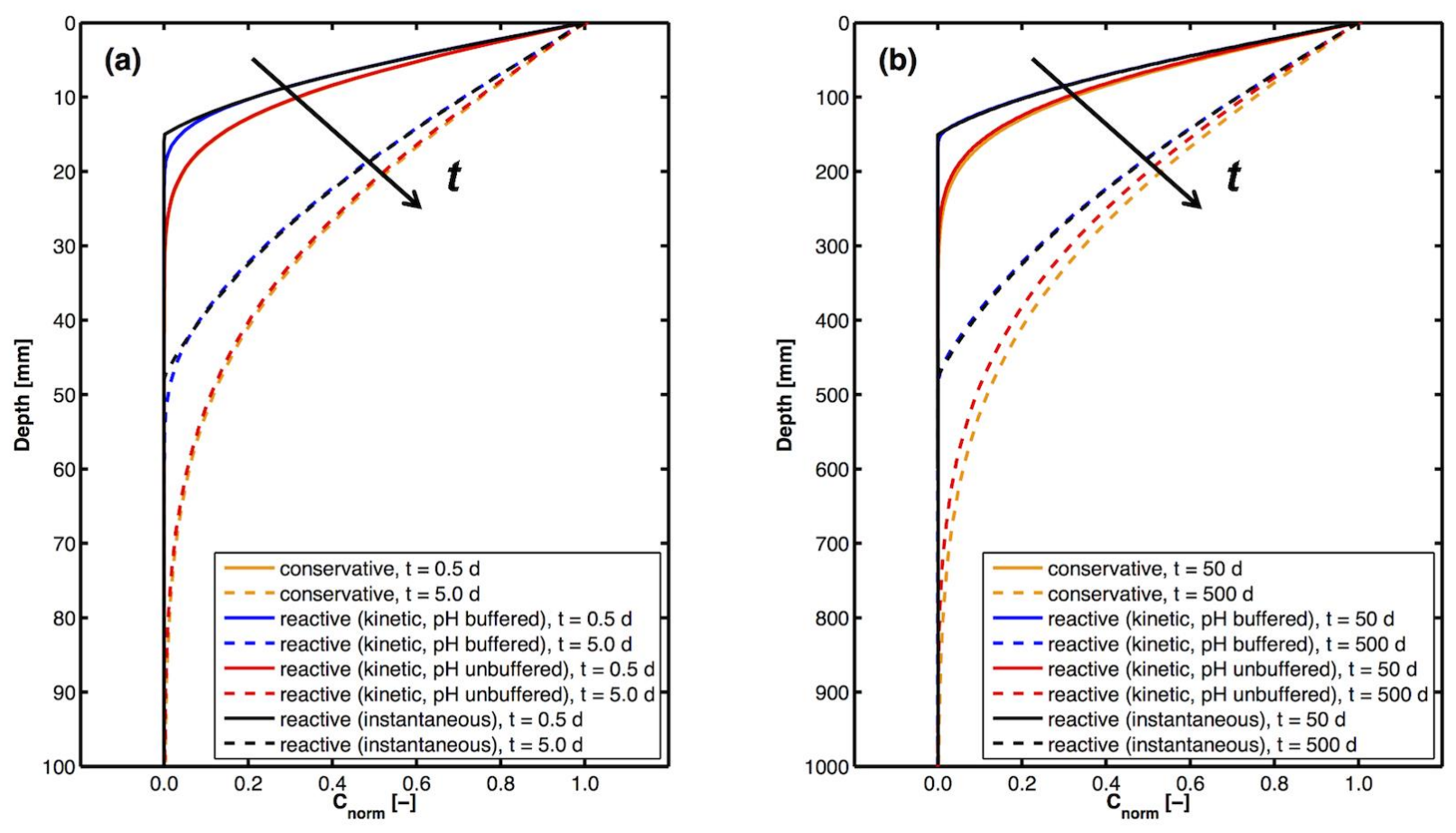

803 Fig. 9: Long-term propagation of oxygen concentration fronts in 1-D diffusive systems. Spatial profiles at (a) 0.5

804 days and 5.0 days, and at (b) 50 days and 500 days. 
(a) Experimental Setup

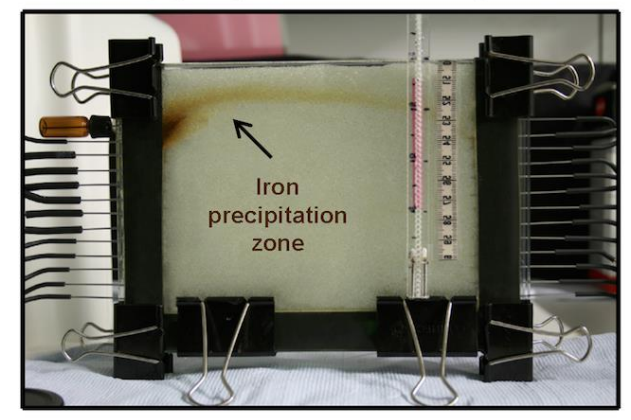

(b) Simulated Streamlines \& Mineral Precipitation

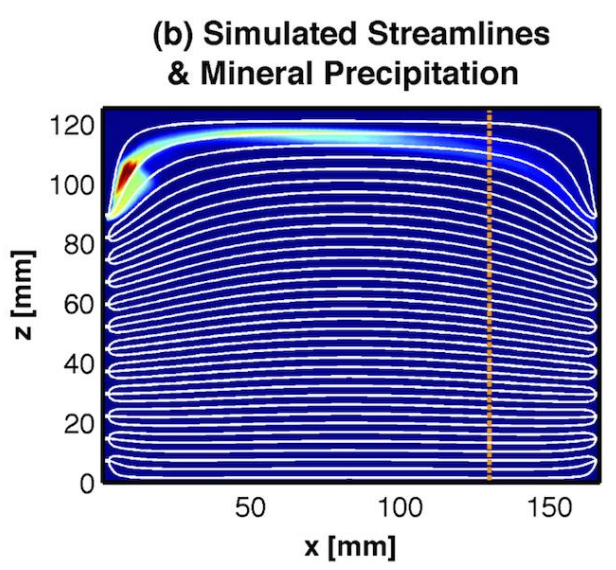

(c) Oxygen Conc. Profiles at $\mathrm{x}=13 \mathrm{~cm}$

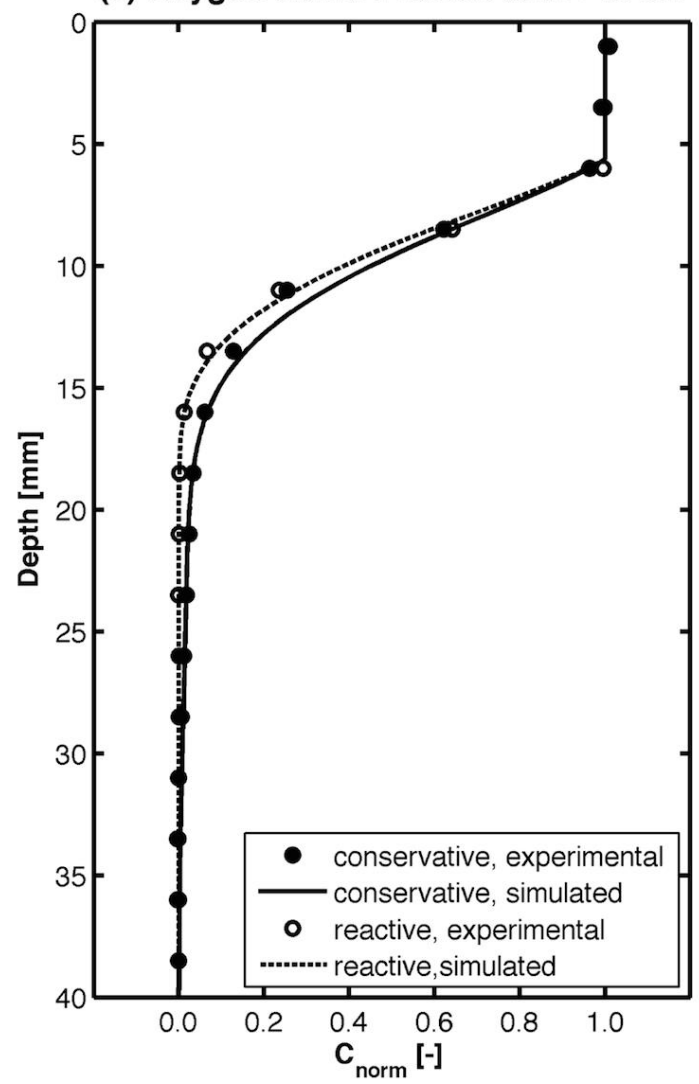

806 Fig. 10: 2-D flow-through experiment: (a) Photograph of the experimental setup during the reactive phase of the

807 experiment (with kinetic iron(II) oxidation and buffered $\mathrm{pH}$ ), (b) simulated flow lines using MODPATH (Pollock,

808 1994) and color map showing the simulated precipitation of ferrihydrite (with maximum concentration close to the

809 inlet: $2.97 \times 10^{-4} \mathrm{~mol} \mathrm{~L}^{-1}$ of bulk volume at 0.2 days). The vertical orange line shows the location of the vertical

810 oxygen-sensitive polymer strip $(x=13 \mathrm{~cm}$ ). (c) Concentration profiles for the conservative and reactive experiments

811 (the y-axis represents the distance from the upper boundary of the flow-through setup). 

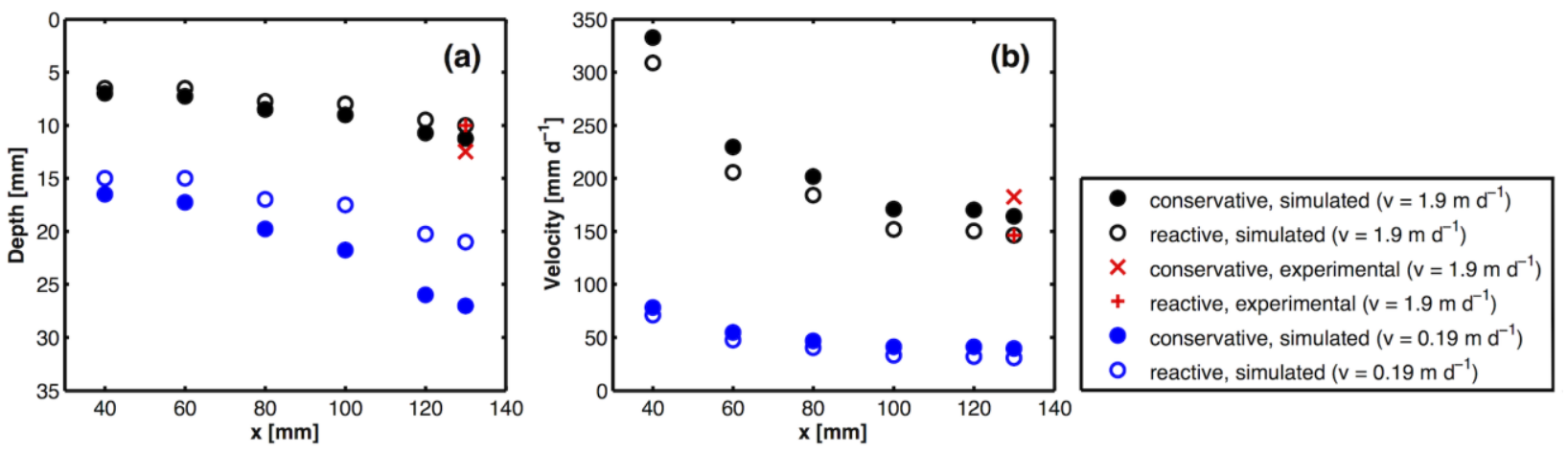

813 Fig. 11: Penetration depth (a) and velocity of propagation of the dispersive oxygen fronts (b) in the quasi 2-D flow-

814 through setup as function of the longitudinal distance from the inlet of the flow-through chamber for two seepage

815 velocities ( $v=1.9$ and $0.19 \mathrm{~m} \mathrm{~d}^{-1}$, respectively). 